\title{
Interacciones entre las sociedades y las plantas durante el Holoceno medio-tardío en el área septentrional del Río de la Plata (Uruguay)
}

\author{
Laura BEOvide y Sara CAMPos \\ Programa de investigación antropo-arqueológica, \\ Dirección de Innovación, Ciencia y Tecnología para el Desarrollo, MEC, Uruguay. \\ beovide@mec.gub.uy
}

Recibido: 10 de marzo de 2014

Aceptado: 23 de mayo de 2014

\section{RESUMEN}

En las últimas dos décadas se han dado a conocer distintos hallazgos de plantas silvestres en relación con cultígenos, que dan cuenta del amplio manejo que tuvieron de ellas las sociedades del Holoceno medio-tardío, vinculadas al litoral del Río de la Plata y áreas adyacentes sobre los ríos Paraná, Uruguay y costa Atlántica

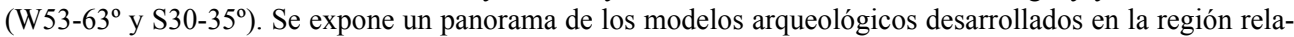
cionados con el rol de la recolección y domesticación de plantas, fundamentalmente desde el Holoceno medio. Se analiza la presencia y trayectoria temprana de cultígenos en la cuenca baja del río Santa Lucía en el marco general de un manejo holístico del entorno vegetal. Se propone que el conocimiento de la domesticación de plantas estuvo presente y extendido en la región platense, como parte de un conjunto vasto de interacciones humanas con las plantas, mucho más tempranamente de lo supuesto con anterioridad.

Palabras clave: Arqueobotánica, domesticación, arqueología de la cuenca del Plata, micro y macro restos vegetales.

\section{Interactions between Societies and Plants during the Mid-Late Holocene in the Northern Area of Rio de la Plata (Uruguay)}

\begin{abstract}
In the last two decades a number findings of wild plants together with cultigens account for the wide usage of plants in the Mid-late Holocene societies who lived on the coast of the Rio de la Plata and adjacent areas of the Parana and Uruguay rivers and the Atlantic coast (W53-63 and S30-35). We present an overview of those archaeological models developed in the region in connection to the role of gathering and domestication from the Mid-Holocene on. We also explore the presence and trajectory of early cultigens in the general framework of a holistic management of the plant environment by analyzing a case in the Archaeology of the Lower Basin of the Santa Lucia River. It is suggested that the knowledge about plant domestication was present and widespread in the Río de la Plata region much earlier than what was being handled by researchers decades ago, as part of a broad set of interactions of those societies with plants.
\end{abstract}

Key words: Archaeobotany, Domestication, Río de la Plata Basin Archaeology, Micro and macro plant remains.

Sumario: 1. Introducción. 2. Visibilidad del registro vegetal en el siglo XIX y XX. 3. El registro arqueobotánico regional asociado a la subsistencia. 4. La trayectoria de las plantas en la cuenca inferior del río Santa Lucía. 5. Discusión. 6. Conclusiones. 7. Referencias bibliográficas.

\section{Introducción}

La región terminal de la cuenca del Plata (Figura 1) ha sido poblada desde fines del Pleistoceno. Lo atestiguan sitios superficiales y estratificados de cazadores-recolectores fechados entre $c a .13000$ y 12000 años AP (López 2013; Miller 1987; Politis 


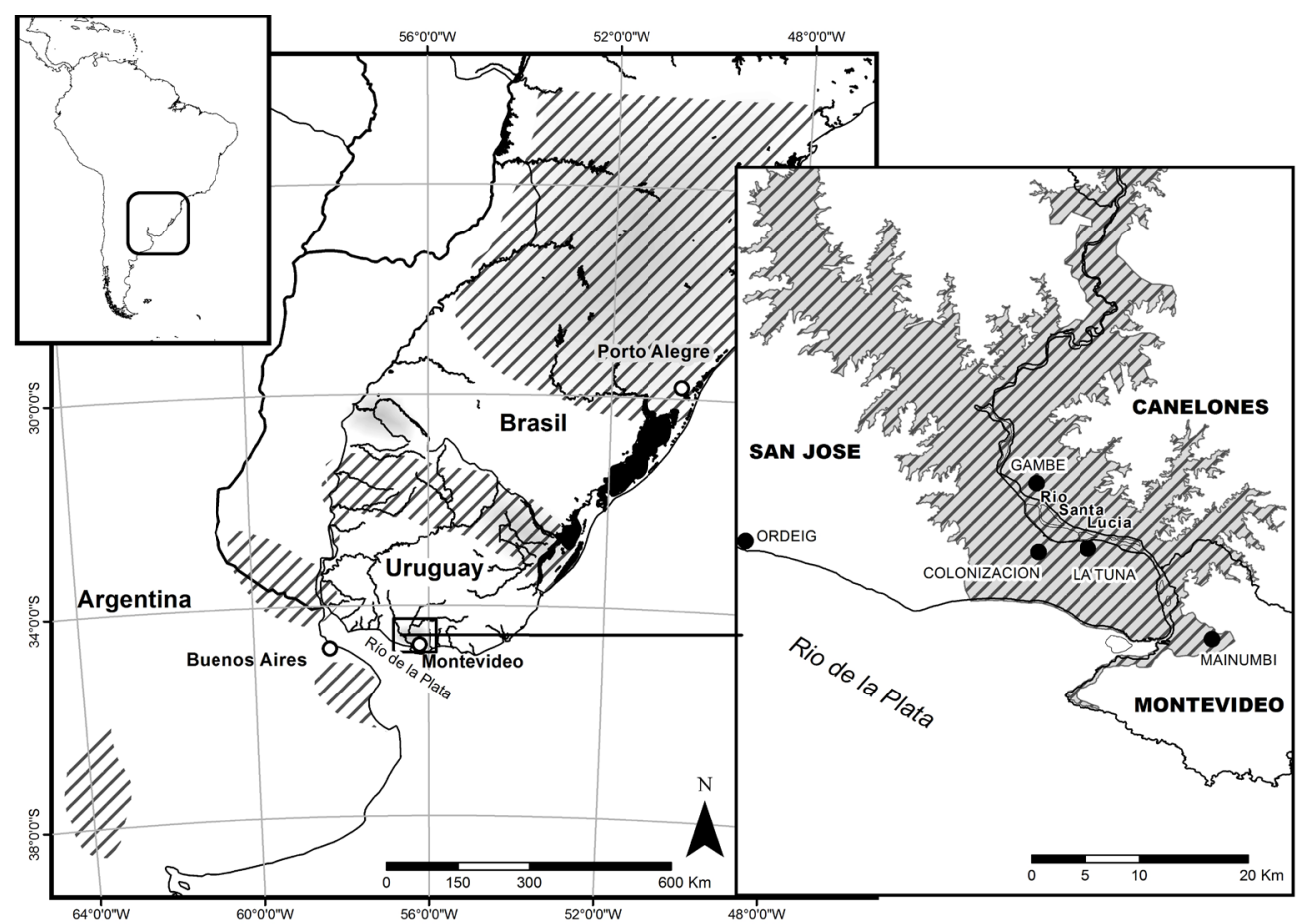

Figura 1: Ubicación del área septentrional del Río de la Plata en el contexto regional. En detalle: algunos de los sitios de la cuenca inferior del río Santa Lucía. Reportes arqueobotánicos de restos de plantas silvestres/cultivadas referidos al Pleistoceno final (en gris), al Holoceno medio (en gris rayado) $y$ al Holoceno final (en rayado).

et al. 2004; Suárez 2011). Hacia el Holoceno medio-tardío se postula la existencia de pueblos asociados a un modo de vida aldeano con mayor grado de integración y diferenciación social que las definidas para los momentos más tempranos de ocupación del área (Iriarte et al. 2004, 2008; López 2001). Su localización en la región se observa principalmente en las tierras bajas (Andrade y López 2000; Beovide 2009, 2011a y 2011b; Bonomo et al. 2011b; Bracco 2006; Gianotti 2000; Iriarte et al. 2004, 2008; López 2001; Loponte et al. 2004). Las estructuras en forma de montículos -túmulos, «cerritos», cierto tipo de concheros- comprendidas en dicho lapso temporal, han sido consideradas manifestaciones, entre otras cosas, de la emergencia de arquitectura monumental y asentamientos complejos (Beovide 2011a; Gianotti 2000; Iriarte et al. 2004, Iriarte 2006a; López 2001).

Hace solo tres décadas se había explorado poco sobre las interacciones de dichas sociedades con el entorno vegetal (Beovide 2011b; Iriarte 2006a). En ese corto lapso se desarrolló la investigación sistemática bajo la influencia de la arqueología procesual y el avance de nuevas técnicas de estudio: silicofitolitos, almidones, polen y antracológicos (Beovide 2011; Bonomo et al. 2011b; Campos et al. 1993, 2001; Iriarte et al. 2004). La recuperación del registro arqueobotánico que se viene desarrollando, apoya la reconstrucción paleoambiental (Beovide 2007, 2011b; Bracco et al. 2005; 
Del Puerto et al. 2013; Iriarte 2006b) y brinda a su vez nuevas aproximaciones a la dieta de las sociedades pasadas (Bracco et al. 2000; Loponte y Acosta 2007). La evidencia vegetal recuperada revela el uso de plantas silvestres desde hace unos 10.000 años, y de plantas cultivadas desde hace unos 5.000 años (Beovide 2011b; Iriarte 2006a; Iriarte et al. 2004).

El objetivo de este trabajo es resumir, a partir de la información disponible y discutir con base en una consideración integral del uso de las plantas, tanto silvestres como cultivadas, las interacciones entre las sociedades prehispánicas y el entorno vegetal, en el área septentrional del Río de la Plata, particularmente en la cuenca baja del río Santa Lucía (Figura 1).

\section{Visibilidad del registro vegetal en el siglo XIX y XX}

La naturaleza en general de la matriz sedimentaria, así como el clima templado y húmedo de la región (W53-63 y S30-35, ver Figura 1) resulta en un limitado número de sitios arqueológicos prehispánicos, en los que se pueden identificar macro restos vegetales. Ello limitó durante mucho tiempo el conocimiento del entorno vegetal pasado y el desarrollo de la Arquebotánica (Beovide 2011b; Campos et al. 1993, 2001; Del Puerto e Inda 2005; Iriarte 2007a; Iriarte y Behling 2007).

La investigación arqueológica de buena parte del siglo XX, de forma acrítica, ha dado al maíz (Zea mays L.) la mayor representatividad vegetal en el registro arqueológico (Beovide 2011b; Iriarte 2007a), infiriéndose a partir de la identificación en los sitios de instrumentos que se asocian tradicionalmente con el procesamiento de vegetales: morteros, manos o metates (Beovide et al. 2007; Capdepont et al. 2005; Tenorio 1999).

En asociación con las escuelas evolucionistas de finales del siglo XIX y principios del siglo XX, se pueden rastrear referencias tempranas de dichas asociaciones conceptuales (Beovide 2011b). En la «Clasificación de los Tiempos Prehistóricos del Plata» (Ameghino 1918), por ejemplo, la presencia en el registro de instrumentos líticos de molienda suponía la existencia de cultivos y un período Neolítico, del mismo modo que en Europa.

Durante la segunda mitad del siglo XX, las escuelas histórico-culturales contemplan asimismo la posibilidad de sociedades prehispánicas hortícolas en el Plata (también a partir de los instrumentos de molienda presentes en el registro), así como contextualizan esa propuesta discutiendo posibles orígenes y la difusión de los cultivos en América (Imbelloni 1939; Bórmida 1964, entre otros). Particularmente hacia 1970, se adoptó un nuevo esquema cronológico-cultural elaborado por Antonio Serrano (1972) para el área del nordeste argentino, pero con una amplia aceptación en la cuenca baja del Plata. En dicho esquema se propuso la existencia de pueblos ceramistas plantadores (Ribereños Plásticos) para el último milenio (Díaz y Fornaro 1977).

Por otra parte, se han desarrollado otras posturas interpretativas que asumen que determinados tipos de cerámica asociados a los instrumentos de molienda y a restos de cultígenos (Zea mays L.) son «marcadores» arqueológicos de la presencia, en el último milenio, de poblaciones guaraníes, chaná-timbúes, entre otras (Bonomo et al. 2011a; Loponte y Acosta 2007; Misión de Rescate Arqueológico 1989; Rodríguez 1992, 2008, 2010; Schmitz 1991). 
Entre 1980 y 1995, en el registro arqueológico de las sociedades constructoras de cerritos del este del Uruguay, se han recuperado macro-restos de butiá (Butia capitata), algo especialmente ponderado como un recurso de importancia en la dieta de dichas sociedades durante el Holoceno medio-tardío (Bracco et al. 2000; Lopez 2001; López y Bracco 1992; Sans 1988). Los estudios de las dos últimas décadas en dicha región, desarrollados desde un marco procesual y acompañados de nuevas técnicas de recuperación de macro y micro-restos vegetales -silicofitolitos y almidones-, han hecho más visible el registro arqueobotánico en la región, con un soporte empírico mayor. En este sentido, hacia fines de la década de 1990 en el área de la cuenca de la Laguna Merín, Uruguay, se identificaron micro-restos de maíz (Zea mays), calabaza (Cucurbita spp.) y porotos (Phaseolus spp.) (Campos et al. 1993, 2001; Olivero y Campos 1997) además de la presencia de silicofitolitos de arecáceas, achira (Canna glauca) y totora (Typha dominguensis).

Estos primeros hallazgos se ampliaron en investigaciones posteriores (Iriarte et al. 2004) especialmente por las implicaciones de la identificación de Zea mays L. cerca de los 4000 años AP. Como consecuencia, se otorgó una nueva jerarquía a la presencia de cultígenos en el área, modificando el paradigma interpretativo de la economía de dichas sociedades. En este sentido el modelo predominante, desarrollado desde la década de 1980, propone que las sociedades constructoras de montículos fueron el fruto de sociedades de cazadores recolectores de alta eficiencia que desarrollaron estrategias de amplio espectro. En principio, dado los abundantes recursos naturales de la región, la demanda del esfuerzo necesario para el cultivo intensivo originaría una relación costo beneficio negativa, por lo que la contribución de los cultivos a la economía de estos grupos sería limitada (Bracco et al. 2000).

En contraposición con esa idea, a partir de la identificación reciente de plantas cultivadas, se ha propuesto que «aproximadamente a los 4190 (14C) años AP, los Ajos se convirtieron en una aldea de plaza circular permanente, y sus habitantes adoptaron los cultivos más tempranos que actualmente se registran en Sudamérica meridional» (Iriarte et al. 2004: 614).

En esta última década, con el aumento de la investigación arqueológica sistemática en la región, han surgido otras perspectivas sobre la profundidad temporal del uso de las plantas y las trayectorias de las interacciones entre estas y las sociedades a las que estuvieron ligadas. Tales aspectos serán analizados en los siguientes apartados.

\section{El registro arqueobotánico regional asociado a la subsistencia}

Desde una mirada diacrónica, el estudio de los vegetales relacionados con la subsistencia se encuentra en una fase temprana de desarrollo en la región (Iriarte y Behling 2007). En el marco de esta fase inicial se puede delinear un panorama de los recursos reportados por distintos investigadores, fundamentalmente para el Holoceno medio y tardío. En la Figura 1 se ubican las áreas en las que se reportan restos vegetales desde el Pleistoceno final - Holoceno tardío, en el contexto arqueológico regional.

Si bien se han realizado estudios de reconstrucción paleoclimática que contemplan el Pleistoceno final-Holoceno, apoyados por el registro vegetal (Bracco et al. 2005; 
Iriarte 2006b), son pocos los estudios que reportan la presencia de plantas hacia el Pleistoceno final-Holoceno temprano. Ello a pesar de que la presencia humana en el área se registra desde hace $c a .13000$ años AP (López 2013; Miller 1987; Politis et al. 2004; Suárez 2011).

Rafael Suárez (2011) menciona que con base en el estudio del registro de polen del sitio Pay Paso (ubicado en las márgenes del Rio Cuareim, en el norte del Uruguay), hacia $c a .10200$ años $\mathrm{C}^{14} \mathrm{AP}$, se reconocieron «dos frutos comestibles, tala (Celtis sp.) y arazá (Psidium sp.)» (Suárez 2011: 78). Estas especies habrían estado disponibles y potencialmente pudieron ser recolectadas, para consumo humano, en la floresta ribereña que iniciaba su desarrollo (Suárez 2011). También se recuperó polen de «plantas adaptadas a suelos húmedos como Ciperáceas y Typha sp.» (Suárez 2011: 77) para el mismo período de tiempo.

Posteriormente se ha señalado el surgimiento en la región de sociedades constructoras de montículos y de aldeas-plaza planificadas, hacia el Holoceno medio (desde ca. 5000-4000 años AP), asociadas a grupos que practicaban una economía mixta (Iriarte et al. 2004, 2008). Para ese período de tiempo se reportan plantas cultivadas o manejadas (Cuadro 1) entre ellas: maíz (Zea mays L.), zapallo (Curubita sp.), achira (Canna sp.), poroto (Phaseolus spp.) (Iriarte et al. 2004), así como ñame (Discorea sp.) y batata (Ipomoea batatas) (Boyadjian 2007; Scheel-Ybert 2001; Scheel-Ybert et al. 2003; Tenorio 1999; Wesolowski 2000, 2007).

Iriarte y Behling (2007), con base en el estudio de polen vinculado a la araucaria (Araucaria angustifolia), han propuesto la práctica de una agricultura de tala y quema $c a .4320$ años AP. Cabe mencionar que para el Holoceno tardío esta práctica es reconocida más ampliamente por otros investigadores en relación con la araucaria (Araucaria angustifolia) (Bitencourt y Krauspenhar 2006; Beber 2005; De Masi 2005; Kern et al. 1989; Ribeiro 1999/2000; Schmitz 2001/2002).

Las semillas o conos de Araucaria angustifolia, y distintas partes de las palmeras como el fruto, tallo y hojas de la butiá (Butia capitata) y de pindó (Syagrus romanzoffiana) se han identificado en sitios arqueológicos de la región tanto en forma de macro-restos como micro-restos vegetales (De Blasis et al. 2007; Del Puerto y Campos 1999; Iriarte 2007a y 2007b; Iriarte et al. 2004; Scheel-Ybert 2001). La identificación hacia momentos tempranos, así como la ubicuidad de las arecáceas en el registro arqueológico regional (Bracco et al. 2000; Del Puerto y Campos 1999; Del Puerto et al. 2000; Iriarte et al. 2004; Iriarte 2006a y 2007a; López 2001; Loponte 2008; Tenorio 1999) son motivo de interés como indicador de un manejo prehispánico de plantas (Loponte 2008). En este sentido, el análisis realizado en la cuenca baja del Paraná para el Holoceno tardío a partir de datos etnográficos y arqueológicos, define dicho recurso como un marcador territorial y grupal, predecible, abundante y de bajo riesgo (Loponte 2008).

En el litoral sur de Brasil (Santa Catarina) se identificó, sobre la base de estudios antracológicos, una especie de mangle (Avicennia sp.) y guaraniná o coronilla, una especie de árbol (Sideroxylon obtusifolium), en sitios arqueológicos desde ca. 5000 años AP. Se ha intepretado como un caso de cultivo o manejo de plantas con el propósito del uso de sus maderas y sus frutos (De Blasis et al. 2007; Scheel-Ybert 2001; Scheel-Ybert et al. 2003). 
Cuadro 1: Restos vegetales relacionados con la subsistencia, recuperados en el registro arqueológico del Holoceno medio en la región

\begin{tabular}{|c|c|c|c|c|c|c|}
\hline Taxón & $\begin{array}{l}\text { Nombre } \\
\text { común }\end{array}$ & $\begin{array}{l}\text { Edad }{ }^{14} \mathrm{C} \\
\text { años } A P\end{array}$ & Sitio & $\begin{array}{l}\text { Locali- } \\
\text { dad }\end{array}$ & País & Referencia \\
\hline Zea mays & maíz & 4190 & Los Ajos & Rocha & Uruguay & $\begin{array}{l}\text { Iriarte } 2007 \mathrm{a} \mathrm{y} \mathrm{b} \\
\text { Iriarte et al. } 2004\end{array}$ \\
\hline Cucurbita spp. & zapallo & 4190 & Los Ajos & Rocha & Uruguay & $\begin{array}{l}\text { Iriarte } 2007 \mathrm{a} \mathrm{y} \mathrm{b} \\
\text { Iriarte et al. } 2004\end{array}$ \\
\hline Butia capitata & butía & $\begin{array}{l}\text { ca. } 4000- \\
3000\end{array}$ & $\begin{array}{l}\text { Los Ajos, Isla Lar- } \\
\text { ga y Mal Abrigo }\end{array}$ & Rocha & Uruguay & $\begin{array}{l}\text { Del Puerto y Campos 1999; } \\
\text { Iriarte } \text { et al. } 2004\end{array}$ \\
\hline $\begin{array}{l}\text { Syagrus } \\
\text { romanzoffiana }\end{array}$ & pindó & $\begin{array}{l}\text { ca. } 4000- \\
3000\end{array}$ & $\begin{array}{l}\text { Los Ajos, Isla Lar- } \\
\text { ga y Mal Abrigo }\end{array}$ & Rocha & Uruguay & $\begin{array}{l}\text { Del Puerto y Campos 1999; } \\
\text { Iriarte } \text { et al. } 2004\end{array}$ \\
\hline Canna sp. & achira & 3660 & Isla Larga & Rocha & Uruguay & $\begin{array}{l}\text { Iriarte } 2007 \mathrm{a} \mathrm{y} \mathrm{b} \\
\text { Iriarte et al. } 2004\end{array}$ \\
\hline Zea mays & maíz & 3600 & Isla Larga & Rocha & Uruguay & $\begin{array}{l}\text { Iriarte } 2007 \mathrm{a} \mathrm{y} \mathrm{b} \text {; } \\
\text { Iriarte et al. } 2004\end{array}$ \\
\hline Zea mays & maíz & ca- 3700 & CG14E01 & Rocha & Uruguay & Del Puerto y Campos 1999 \\
\hline Phaseolus spp. & poroto & ca- 3700 & CG14E01 & Rocha & Uruguay & Del Puerto y Campos 1999 \\
\hline Cucurbita spp. & zapallo & ca- 3700 & CG14E01 & Rocha & Uruguay & Del Puerto y Campos 1999 \\
\hline Cucurbita spp. & zapallo & 3900 & Gruta do Gentio & $\begin{array}{l}\text { Minas } \\
\text { Gerais* }\end{array}$ & Brasil & Tenorio 1999 \\
\hline Arachis hypogaea & maní & 3901 & Gruta do Gentio & $\begin{array}{l}\text { Minas } \\
\text { Gerais* }\end{array}$ & Brasil & Tenorio 1999 \\
\hline Zea mays & maíz & 3902 & Gruta do Gentio & $\begin{array}{l}\text { Minas } \\
\text { Gerais* }\end{array}$ & Brasil & Tenorio 1999 \\
\hline Discorea sp. & ñame & $\begin{array}{l}2890 \pm 55- \\
1805 \pm 65 \\
5895 \pm 45- \\
4511 \pm 32\end{array}$ & $\begin{array}{l}\text { Jabuticabeira II } \\
\text { e Moraes }\end{array}$ & $\begin{array}{l}\text { Santa } \\
\text { Catarina }\end{array}$ & Brasil & $\begin{array}{l}\text { Wesolowski 2000, 2007; } \\
\text { Scheel-Ybert 2001; } \\
\text { Scheel-Ybert et al. 2003; } \\
\text { Boyadjian } 2007\end{array}$ \\
\hline Arecácea & palmera & $\begin{array}{l}5895 \pm 45- \\
4511 \pm 32\end{array}$ & $\begin{array}{l}\text { Jabuticabeira II } \\
\text { e Moraes }\end{array}$ & $\begin{array}{l}\text { Santa } \\
\text { Catarina }\end{array}$ & Brasil & $\begin{array}{l}\text { Wesolowski 2000, 2007; } \\
\text { Scheel-Ybert 2001; } \\
\text { Scheel-Ybert et al. 2003; } \\
\text { Boyadjian } 2007\end{array}$ \\
\hline Ipomoea batatas & batata & $\begin{array}{l}5895 \pm 45- \\
4511 \pm 32\end{array}$ & $\begin{array}{l}\text { Jabuticabeira II } \\
\text { e Moraes }\end{array}$ & $\begin{array}{l}\text { Santa } \\
\text { Catarina }\end{array}$ & Brasil & $\begin{array}{l}\text { Wesolwski 2000, 2007; } \\
\text { Scheel-Ybert 2001; } \\
\text { Scheel-Ybert et al. 2003; } \\
\text { Boyadjian } 2007\end{array}$ \\
\hline $\begin{array}{l}\text { Araucaria } \\
\text { angustifolia }\end{array}$ & $\begin{array}{l}\text { curý o } \\
\text { «pino } \\
\text { paraná» }\end{array}$ & $\begin{array}{l}c a .4300- \\
200\end{array}$ & $\begin{array}{l}\text { Serra Campos } \\
\text { Gerais; Serra da } \\
\text { Boa Vista; } \\
\text { Morro da Igreja; } \\
\text { Serra do Rio Ras- } \\
\text { tro; Aparados da } \\
\text { Serra; Cambara' do } \\
\text { Sul; Sao Francisco } \\
\text { de Paula; Terra de } \\
\text { Areia; Lagoa dos } \\
\text { Patos; Sao Francis- } \\
\text { co de Assis }\end{array}$ & $\begin{array}{l}\text { Rio } \\
\text { Grande do } \\
\text { Sul, Santa } \\
\text { Catarina, y } \\
\text { Paraná }\end{array}$ & Brasil & Iriarte y Behling 2007 \\
\hline
\end{tabular}

*Adyacente a la región de estudio.

Entre el tercer y segundo milenio antes del presente se observa un fenómeno de mayor expansión: construcción de montículos, desarrollo de concheros, ocupación de las tierras bajas como producto del gradual y fluctuante descenso del nivel del mar desde el óptimo climático, presencia de alfarería y cultígenos en sociedades con me- 
Cuadro 2: Restos vegetales relacionados con la subsistencia, recuperados en el registro arqueológico regional, entre $c a$. 3000 y 1000 años AP

\begin{tabular}{|c|c|c|c|c|c|c|}
\hline Taxón & $\begin{array}{l}\text { Nombre } \\
\text { común }\end{array}$ & $\begin{array}{l}\text { Edad }{ }^{14} \mathrm{C} \\
\text { años } \mathrm{AP}\end{array}$ & Sitio & $\begin{array}{l}\text { Locali- } \\
\text { dad }\end{array}$ & País & Referencia \\
\hline Phaseolus spp. & poroto & 3050 & Isla Larga & Rocha & Uruguay & Iriarte et al. 2001 \\
\hline Zea mays & maíz & 2800 & Los Indios & Rocha & Uruguay & Iriarte et al. 2004 \\
\hline Zea mays & maíz & ca. $3000-500$ & Yale 27 & $\begin{array}{l}\text { Tacuar- } \\
\text { embó }\end{array}$ & Uruguay & $\begin{array}{l}\text { Gianotti 2000, 2005; } \\
\text { Del Puerto e Inda 2005 }\end{array}$ \\
\hline Canna sp. & achira & ca. $3000-500$ & Yale 27 & $\begin{array}{l}\text { Tacuar- } \\
\text { embó }\end{array}$ & Uruguay & $\begin{array}{l}\text { Gianotti 2000, 2005; } \\
\text { Del Puerto e Inda 2005 }\end{array}$ \\
\hline Zea mays & maíz & ca. 3700 & CG14E01 & Rocha & Uruguay & Del Puerto y Campos 1999 \\
\hline Phaseolus spp. & poroto & ca. 3700 & CG14E01 & Rocha & Uruguay & Del Puerto y Campos 1999 \\
\hline Cucurbita spp. & zapallo & ca. 3700 & CG14E01 & Rocha & Uruguay & Del Puerto y Campos 1999 \\
\hline Zea mays & maíz & ca. 3000 y 500 & $\begin{array}{l}\text { Cráneo Marcado / } \\
\text { Guardia del Monte }\end{array}$ & Rocha & Uruguay & Del Puerto y Campos 1999 \\
\hline Phaseolus spp. & poroto & ca. 3000 y 500 & Cráneo Marcado & Rocha & Uruguay & Del Puerto y Campos 1999 \\
\hline Cucurbita spp. & zapallo & ca. 3000 y 500 & Cráneo Marcado & Rocha & Uruguay & Del Puerto y Campos 1999 \\
\hline Discorea sp. & ñame & $\begin{array}{l}2890 \pm 55- \\
1805 \pm 65\end{array}$ & $\begin{array}{l}\text { Jabuticabeira II e } \\
\text { Moraes }\end{array}$ & $\begin{array}{l}\text { Santa } \\
\text { Catarina }\end{array}$ & Brasil & $\begin{array}{l}\text { Wesolowski 2000, 2007; } \\
\text { Scheel-Ybert 2001; } \\
\text { Scheel-Ybert et al. 2003; } \\
\text { Boyadjian } 2007\end{array}$ \\
\hline Aracae sp. & & $\begin{array}{l}2890 \pm 55 \\
1805 \pm 65\end{array}$ & $\begin{array}{l}\text { Jabuticabeira II e } \\
\text { Moraes }\end{array}$ & $\begin{array}{l}\text { Santa } \\
\text { Catarina }\end{array}$ & Brasil & $\begin{array}{l}\text { Wesolowski 2000, 2007; } \\
\text { Scheel-Ybert 2001; } \\
\text { Scheel-Ybert et al. 2003; } \\
\text { Boyadjian } 2007\end{array}$ \\
\hline Ipomoea batatas & batata & $\begin{array}{l}2890 \pm 55 \\
1805 \pm 65\end{array}$ & $\begin{array}{l}\text { Jabuticabeira II e } \\
\text { Moraes }\end{array}$ & $\begin{array}{l}\text { Santa } \\
\text { Catarina }\end{array}$ & Brasil & $\begin{array}{l}\text { Wesolowski 2000, 2007; } \\
\text { Scheel-Ybert 2001; } \\
\text { Scheel-Ybert et al. 2003; } \\
\text { Boyadjian } 2007\end{array}$ \\
\hline $\begin{array}{l}\text { Ciperáceas, } \\
\text { arecaceas, Butia } \\
\text { capitata, Bro- } \\
\text { melia } \text { sp., Celtis } \\
\text { spinosa, Celtis } \\
\text { tala, Cyperus sp. }\end{array}$ & $\begin{array}{l}\text { juncos, } \\
\text { totora, } \\
\text { palmeras, } \\
\text { butiá, } \\
\text { brome- } \\
\text { lias, tala }\end{array}$ & ca. 3000 y 500 & $\begin{array}{l}\text { Guardia del } \\
\text { Monte / } \\
\text { Cráneo Marcado }\end{array}$ & Rocha & Uruguay & Capdepont et al. 2005 \\
\hline $\begin{array}{l}\text { Typha domin- } \\
\text { guensis, } \\
\text { Arecáceas, }\end{array}$ & $\begin{array}{l}\text { palmeras } \\
\text { y totora }\end{array}$ & ca. 3000 y 500 & Yale 27 & $\begin{array}{l}\text { Tacuar- } \\
\text { embó }\end{array}$ & Uruguay & $\begin{array}{l}\text { Gianotti 2000, 2005; } \\
\text { Del Puerto e Inda 2005 }\end{array}$ \\
\hline Ilex & yerba & ca. 3000 y 500 & Cráneo Marcado & Rocha & Uruguay & Capdepont et al. 2005 \\
\hline Canna sp. & achira & ca. 3000 y 500 & $\begin{array}{l}\text { Guardia del Monte / } \\
\text { Cráneo Marcado }\end{array}$ & Rocha & Uruguay & Capdepont et al. 2005 \\
\hline
\end{tabular}

nos movilidad residencial (Beovide 2009, 2011b; Bracco 2006; Bracco et al. 2005; Gianotti 2000; Iriarte 2006a, 2007a; Iriarte et al. 2004; Iriarte y Behling 2007; López 2001; Schmitz 2001/2002). En el registro arqueobotánico asociado a la subsistencia para dicho período, los registros se refieren a la presencia de cultígenos como: maíz (Zea mays), achira (Canna sp.), porotos (Phaseolus spp.), zapallo (Cucurbita spp.), así como ñame (Discorea sp.) y batatas (Ipomoea batatas) (Boyadjian 2007; Del Puerto y Campos 1999; Gianotti 2000; Iriarte 2006a, 2007a; Iriarte et al. 2001; López 2001; Scheel-Ybert et al. 2003; Wesolowski 2000, 2007).

Además de las especies ya mencionadas se reportan distintas palmeras (Butia capitata y Syagrus romanzoffiana), tala (Celtis tala) y bromelia (Bromelia sp.), (Typha dominguensis) que presentan un potencial uso alimenticio (harinas, frutos, entre 
otros) y tecnológico (Boyadjian 2007; Capdepont et al. 2005; Del Puerto y Campos 1999; Iriarte 2006a, 2006b, 2007a, 2007b; Scheel-Ybert 2001; Scheel-Ybert et al. 2003; Wesolowski 2000, 2007).

Para el último milenio antes del presente, se ha propuesto la existencia en la región de centros ceremoniales asociados a monumentos funerarios, festejos rituales y complejos de recintos (túmulos, casas pozo). Ello reflejaría la jerarquización social incipiente, la territorialidad y la ideología vinculada a la presencia de cacicazgos o jefaturas (Bonomo et al. 2011a, 2011b, 2011c; Gianotti 2000; Iriarte 2006a; Iriarte et al. 2008; 2010; López 2001; Loponte y Acosta 2007). Para dicho período y el previo a la conquista europea, se percibe a la cuenca del Río de la Plata como un espacio donde las sociedades provenientes de distintos ambientes convergieron e interactuaron (Iriarte et al. 2008).

Cuadro 3: Restos vegetales relacionados con la subsistencia (fundamentalmente plantas manejadas y cultígenos) recuperadas en el registro arqueológico $c a$. 1000 años AP en la región

\begin{tabular}{|c|c|c|c|c|c|c|}
\hline Taxón & $\begin{array}{c}\text { Nombre } \\
\text { común }\end{array}$ & $\begin{array}{l}\text { Edad }{ }^{14} C \\
\text { años } A P\end{array}$ & $\begin{array}{l}\text { Sitio/localidad } \\
\text { arqueológica }\end{array}$ & $\begin{array}{l}\text { Locali- } \\
\text { dad }\end{array}$ & País & Referencia \\
\hline $\begin{array}{l}\text { Calathea spp., } \\
\text { Phaseolus spp. }\end{array}$ & $\begin{array}{l}\text { lerén, } \\
\text { poroto }\end{array}$ & 1190 & $\begin{array}{l}\text { Isla Larga y Los } \\
\text { Indios }\end{array}$ & Rocha & Uruguay & Iriarte et al. 2001 \\
\hline $\begin{array}{l}\text { Zea mays, } \\
\text { Phaseolus } \\
\text { vulgaris }\end{array}$ & $\begin{array}{l}\text { maíz, } \\
\text { poroto }\end{array}$ & ca. $700-500$ & $\begin{array}{l}\text { Cerro Tapera Váz- } \\
\text { quez, Brazo Largo } \\
\text { y del Río Paraná } \\
\text { Miní. }\end{array}$ & Entre Ríos & Argentina & Bonomo et al. 2010a, b y c \\
\hline $\begin{array}{l}\text { Zea mays, } \\
\text { Cucurbita spp. }\end{array}$ & $\begin{array}{l}\text { maíz, } \\
\text { zapallo }\end{array}$ & 1810 & $\begin{array}{l}\text { Abrigo do Mate- } \\
\text { matico }\end{array}$ & $\begin{array}{l}\text { Río } \\
\text { Grande do } \\
\text { Soul }\end{array}$ & Brasil & Miller 1971 \\
\hline Zea mays & maíz & 1950 & $\begin{array}{l}\text { San Francisco de } \\
\text { Assis }\end{array}$ & $\begin{array}{l}\text { Río } \\
\text { Grande do } \\
\text { Soul }\end{array}$ & Brasil & Behling et al. 2005 \\
\hline $\begin{array}{l}\text { Zea mays, } \\
\text { Cucurbita spp. }\end{array}$ & $\begin{array}{l}\text { maíz, } \\
\text { zapallo }\end{array}$ & $870 \pm 100$ & El Puente & Rio Negro & Uruguay & Castillos 2004 \\
\hline $\begin{array}{l}\text { Zea mays, } \\
\text { Phaseolus spp., } \\
\text { Cucurbita } \text { spp. }\end{array}$ & $\begin{array}{l}\text { maíz, } \\
\text { poroto, } \\
\text { zapallo }\end{array}$ & ca. $2400-500$ & $\mathrm{CH} 2 \mathrm{D} 01$ & Rocha & Uruguay & Del Puerto y Campos 1999 \\
\hline Zea mays & maíz & ca. 3000 y 500 & Guardia del Monte & Rocha & Uruguay & $\begin{array}{l}\text { Capdepont y Pintos 2007; } \\
\text { Capdepont et al. } 2005\end{array}$ \\
\hline Zea mays & maíz & $885 \pm 35$ & $\begin{array}{l}\text { Cañada de los } \\
\text { Caponcitos }\end{array}$ & $\begin{array}{l}\text { Tacuar- } \\
\text { embó }\end{array}$ & Uruguay & Gianotti et al. 2013 \\
\hline Canna sp. & achira & $885 \pm 35$ & $\begin{array}{l}\text { Cañada de los } \\
\text { Caponcitos }\end{array}$ & $\begin{array}{l}\text { Tacuar- } \\
\text { embó }\end{array}$ & Uruguay & Gianotti et al. 2013 \\
\hline Zea mays & maíz & $700-400$ & Guayacas & Paysandú & Uruguay & Capdepont 2013 \\
\hline $\begin{array}{l}\text { Ilex, } \\
\text { Canna sp. }\end{array}$ & $\begin{array}{l}\text { yerba, } \\
\text { achira }\end{array}$ & ca. 3000 y 500 & $\begin{array}{l}\text { Guardia del Monte } \\
\text { / } \\
\text { Craneo Marcado }\end{array}$ & Rocha & Uruguay & Capdepont et al. 2005 \\
\hline $\begin{array}{l}\text { Cucurbitas, } \\
\text { Phaseolus sp. } \\
\text { Zea mays L }\end{array}$ & zapallo & ca. 1200 a 360 & $\begin{array}{l}\text { Distintos sitios en } \\
\text { el área pampeana }\end{array}$ & La Pampa & Argentina & $\begin{array}{l}\text { Illescas et al. 2012; } \\
\text { Berón } 2013\end{array}$ \\
\hline Zea mays & maíz & $800-900$ & $\begin{array}{l}\text { Sitios del Delta } \\
\text { inferior del Paraná }\end{array}$ & $\begin{array}{l}\text { Delta del } \\
\text { Paraná }\end{array}$ & Argentina & $\begin{array}{l}\text { Loponte 2008; } \\
\text { Loponte y Acosta } 2007\end{array}$ \\
\hline Zea mays & maíz & $2500-500$ & $\begin{array}{l}\text { Colonia Concordia/ } \\
\text { d13C. }\end{array}$ & $\begin{array}{l}\text { Suroeste } \\
\text { del Uru- } \\
\text { guay }\end{array}$ & Uruguay & Bracco et al. 2000 \\
\hline
\end{tabular}


En este sentido, algunos investigadores reelaboraron, con base en ideas que se remontan a los siglos XIX y XX, distintos esquemas que vinculan el registro arqueológico con el etnohistórico. Así han resaltado las posibles continuidades culturales e históricas del pasado prehispánico en relación con ciertos grupos: Tupí-Guaraní, de filiación Arawak, Jê meridionales, Kaingang y Minuanes, entre otros (Bonomo et al. 2011a, 2011c; Iriarte et al. 2008; López y Bracco 2010; Loponte y Acosta 2007). Se han desarrollado visiones críticas de estas posturas cuestionándose, entre otras cosas, la construcción arqueológica sobre las etnias y «lo guaraní» en el área, exponiendo una vía alternativa para discutir las inferencias al respecto (Beovide 2003; Farías 2005).

En el Cuadro 3 se mencionan algunas de las plantas manejadas o cultivadas ( $c a$. 1500-400 años AP) reportadas para la región como: maíz (Zea mays), porotos (Phaseolus vulgaris), lerén (Calathea spp.), achira (Canna sp.) y zapallo (Cucurbita spp.) (Behling et al. 2005; Berón 2013; Bonomo et al. 2011a, 2011b, 2011c; Bracco et al. 2000; Capdepont 2013; Capdepont y Pintos 2007; Capdepont et al. 2005; Castillos 2004; Del Puerto y Campos 1999; Gianotti et al. 2013; Illescas et al. 2012; Iriarte et al. 2001; Loponte 2008; Loponte y Acosta 2007; Miller 1971). Cabe mencionar la identificación de oryzoideas en algunos sitios de la región de las que se postula una eventual explotación (Sánchez et al. 2013).

Se han identificado plantas con potencial de uso para la subsistencia tales como: tala (Celtis tala) (Babot et al. 2007, Capdepont et al. 2005, González 2005, González y Frere 2009, Meroni et al. 2010), molle (Schinus sp.), sauce (Salix sp.) (González 2005, González y Frere 2009), sombra de toro (Jodinia rhombifolia) y papa del aire (Sechium edule) (Meroni et al. 2010). También laurel (Ocotea sp.), pasionaria (Passiflora), timbo colorado (Enterolobium sp.), algarrobo (Prosopis sp.), espinillo (Acacia caven), ceibo (Erythrina sp.), curupí (Sapium sp.), petiribi o peterebi (Cordia sp.) y papiro criollo (Cyperus) (Brea et al. 2013). Por último, palmeras como Syagrus romanzoffiana, Butia capitata y Butia yatay se han identificado en diversos sitios de la región (Bracco et al. 2000; Capdepont 2013; Capdepont et al. 2005; Del Puerto y Campos 1999; Del Puerto e Inda 2005; Farías 2005; Iriarte et al. 2001; López 2001; Loponte 2008; Zucol et al. 2008).

\section{La trayectoria de las plantas en la cuenca inferior del río Santa Lucía}

En el siguiente apartado se explora el registro arqueobotánico de la cuenca inferior del Río Santa Lucía, tributario del Río de la Plata (Figura 1). Se reconocen, por un lado, muchas de las plantas reportadas en los sitios de la región desde el Holoceno medio, y por otro, las particularidades locales, ambientales y culturales de dicho registro.

Hacia el Holoceno medio, la costa del Río de la Plata experimentó el efecto del máximo ingresivo (óptimo climático), provocando el aumento del nivel del mar la inundación de las tierras bajas circundantes (Bracco et al. 2005; Cavallotto et al. 2004; Martínez et al. 2006). El actual río Santa Lucía, entre los ca. 6000 y 5000 años AP, se presenta como un estuario, ya que el nivel del mar alcanza cotas entre $c a .+5$ 
$\mathrm{y}+10 \mathrm{~m}$ (dependiendo de las singularidades del paisaje) y se extiende casi $40 \mathrm{~km}$ desde su actual desembocadura (Beovide 2007, 2009; Beovide et al. 2010a; Coronel et al. 1980). Se propone que las sociedades humanas más tempranas se ubicaron en las márgenes de dicho estuario y se fueron extendiendo hacia las tierras bajas de la cuenca, a medida que iba descendiendo el nivel del mar (Beovide 2009).

La ocupación más temprana, ubicada hacia $c a$. 4800 años AP, se considera asociada a pueblos que presentan alfarería así como cultígenos y que hacen uso de los recursos naturales en radios de 10 a $200 \mathrm{~km}$ desde los asentamientos (Beovide 2009, 2011a, 2011b). El uso de rocas, flora y fauna en esos radios de $10 \mathrm{~km}$ sugiere un conocimiento significativo del registro geológico y una adaptación a dichos ambientes (Beovide et al. 2010a, 2010b).

Puerto La Tuna (Figura 1) es el sitio arqueológico mejor estudiado de este período (Beovide 2007, 2009, 2011a, 2011b; Beovide et al. 2010a y 2011b). Se ubica en una punta arenosa, de $c a .500 \mathrm{~m}^{2}$ y en cotas de $c a .2,5$ a $10 \mathrm{msnm}$, limitada por los humedales que bordean al actual río Santa Lucía. La punta arenosa se fue conformando posteriormente al máximo ingresivo holocénico, a medida que se producía el descenso del mar. Los espacios ganados al mismo fueron ocupados gradualmente entre los ca. 5000 y 400 años AP (Beovide 2009; Beovide et al. 2009, 2010a, 2010b). Las evidencias arqueológicas del momento de ocupación más temprano de Puerto La Tuna se ubican en un paleosuelo por encima de los $5 \mathrm{msnm}$, a casi 1000 metros de distancia del actual río y a $10 \mathrm{~km}$ de su desembocadura en el Río de la Plata.

En el contexto arqueológico regional, la cerámica temprana se asocia al cuarto y tercer milenio AP (Politis et al. 2001). Sin embargo, la cerámica identificada en el sitio Puerto La Tuna extiende el piso temporal de la misma al quinto milenio antes del presente (Beovide 2009, 2011a; Beovide et al. 2009, 2010b). Del contexto cerámico de ca. 4800 años AP (acotado por fechados radiocarbónicos) se infiere: a) que el abastecimiento de arcillas para la alfarería comprendió un radio de menos de $1 \mathrm{~km}$ desde el sitio (Beovide et al. 2010b); y b) que en el mismo se habrían realizado todas las etapas de producción cerámica (Beovide 2011a; Beovide et al. 2009, 2010b). No queda claro en los estudios tecnológicos que la arena fuera el principal antiplástico introducido, ya que puede no haber sido un agregado intencional a la pasta cerámica (Beovide et al. 2009). Se identificaron también pigmentos minerales (fundamentalmente hematita) de menor abundancia que los correspondientes a los momentos más tardíos de ocupación del sitio (ca. 700 a 400 años AP) (Beovide 2011a; Beovide et al. 2009).

Debido al $\mathrm{pH}$ ácido del suelo, la fauna recuperada es escasa y remite fundamentalmente a peces. La corvina negra (Pogonias cromis) es la mejor representada en el registro, lo que pudo haber implicado un recurso de buen porte $(20 \mathrm{a} 30 \mathrm{~kg})$ en la subsistencia del grupo (Beovide 2011a; Beovide et al. 2009, 2010b).

En cuanto a los vegetales (Cuadro 4, Figura 2), se recuperaron macro restos quemados de tuna (Opuntia sp.) y palmera pindó (Syagrus romanzofiana) (Beovide 2011a, 2011b; Beovide et al. 2009, 2010b; Campos 2013). En los sedimentos del contexto de ca. 4800 años AP se identificaron silicofitolitos de achira (Canna sp.), pindó y Ciperáceas. En un fragmento de mano de moler se reconocieron silicofitolitos de zapallo (Cucurbita sp.) y tala (Celtis tala), almidones de batata (Ipomea batatas) y microcarbones. En la parte punzante de un perforador de cuarzo se identificaron granos de almidones (Campos 2013). 
Cuadro 4: Vegetales identificados en el contexto de $c a$. 4800 años AP del sitio Puerto La Tuna, con importancia para la subsistencia

\begin{tabular}{|c|c|c|c|c|c|c|c|}
\hline Taxón & $\begin{array}{l}\text { Nombre } \\
\text { común }\end{array}$ & $\begin{array}{c}\text { Micro-restos } \\
\text { botánicos }\end{array}$ & $\begin{array}{l}\text { Edad }{ }^{14} \mathrm{C} \\
\operatorname{años} \mathrm{AP}\end{array}$ & Sitio & $\begin{array}{l}\text { Exca- } \\
\text { vación }\end{array}$ & Muestra & Referencia \\
\hline & granos & almidones & ca. 4800 & La Tuna & I & $\begin{array}{l}\text { artefacto } \\
\text { punzante }\end{array}$ & Campos 2013 \\
\hline Celtis tala & tala & silicofitolitos & ca. 4800 & La Tuna & III & $\begin{array}{l}\text { mano de } \\
\text { moler }\end{array}$ & Campos 2013 \\
\hline Cucurbita sp. & $\begin{array}{l}\text { zapallo, cás- } \\
\text { cara y pelo } \\
\text { segmentado }\end{array}$ & silicofitolitos & ca. 4800 & La Tuna & III & $\begin{array}{l}\text { mano de } \\
\text { moler }\end{array}$ & $\begin{array}{l}\text { Beovide 2011a y b; } \\
\text { Beovide et al. } 2009\end{array}$ \\
\hline $\begin{array}{l}\text { Ipomoea } \\
\text { batatas }\end{array}$ & boniato & almidón & ca. 4800 & La Tuna & III & $\begin{array}{l}\text { mano de } \\
\text { moler }\end{array}$ & Campos 2013 \\
\hline Canna sp. & achira & silicofitolitos & ca. 4800 & La Tuna & III & sedimentos & $\begin{array}{l}\text { Beovide } 2011 \mathrm{a} \text { y b; } \\
\text { Beovide } \text { et al. } 2009\end{array}$ \\
\hline Ciperáceas & & silicofitolitos & ca. 4800 & La Tuna & III & sedimentos & $\begin{array}{l}\text { Beovide } 2011 \mathrm{a} \mathrm{y} \mathrm{b} \text {; } \\
\text { Beovide et al. } 2009\end{array}$ \\
\hline Canna sp. & & silicofitolitos & ca. 4800 & La Tuna & III & sedimentos & $\begin{array}{l}\text { Beovide } 2011 \mathrm{a} \mathrm{y} \mathrm{b} \\
\text { Beovide } \text { et al. } 2009\end{array}$ \\
\hline $\begin{array}{l}\text { Syagrus } \\
\text { romanzoffiana }\end{array}$ & $\begin{array}{l}\text { pindó } \\
\text { (fruto y hoja) }\end{array}$ & silicofitolitos & ca. 4800 & La Tuna & I & sedimentos & $\begin{array}{l}\text { Beovide } 2011 \mathrm{a} \mathrm{y} \mathrm{b} \\
\text { Beovide } \text { et al. } 2009\end{array}$ \\
\hline Ciperáceas & & silicofitolitos & ca. 4800 & La Tuna & I & sedimentos & $\begin{array}{l}\text { Beovide } 2011 \mathrm{a} \text { y b; } \\
\text { Beovide } \text { et al. } 2009\end{array}$ \\
\hline
\end{tabular}

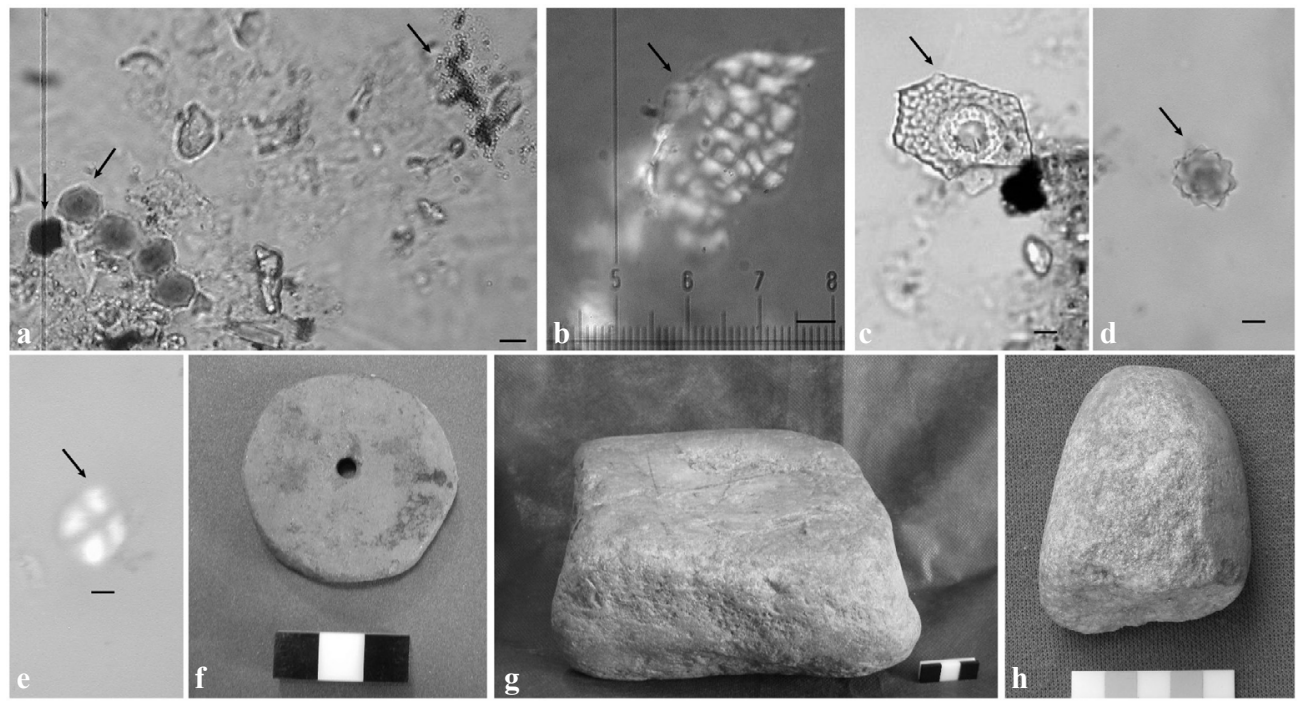

Figura 2: Algunas muestras de micro-restos e instrumentos asociados al procesamiento y uso de plantas (cuenca inferior del río Santa Lucía, ca. 5000 y 400 años AP). Escala $5 \mu \mathrm{m}, 400 \mathrm{X}$ para figuras a-e, y escala en $\mathrm{cm}$ para figuras de $\mathrm{f}$ a h. En a) de izquierda a derecha micro-carbón, silicofitolito de Canna sp. y estructura asociada al proceso de molienda (sedimentos, sitio Puerto La Tuna, ca. 4800 años AP), b) almidón gelatinizado en mano de moler (sitio Puerto La Tuna, $c a .4800$ añosAP), c) silicofitolito de Ciperácea (sedimentos, sitio Puerto La Tuna, ca. 4800 años AP), d) silicofitolito de Syagrus romanzoffiana en mano de moler (sitio Colonización ca. 3000 años AP), e) almidón de Zea mays en mano de moler (sitio Gambé $c a$. 3000 años AP), f) tortero de cerámica (Sitio Puerto La Tuna, ca. 700-400 años AP), g) artefacto compuesto (mortero/piedra con hoyuelo, sitio Colonización, $c a$. 3000-200 años AP) de granito, h) mano de moler de cuarzo (sitio Gambé, $c a .3000$ años AP). 
Es significativa la presencia de batata (Ipomoea batatas) y achira (Canna sp.), ya que de sus rizomas (gruesos y de buen porte) se obtienen harinas. Los procedimientos tradicionales utilizados en la actualidad en distintos puntos de América para la preparación de harinas, involucran la separación de las cáscaras de los rizomas por hervido o pelado, mientras que la pulpa es machacada y dejada secar.

Silicofitolitos de Canna sp. y estructuras asociadas a la acción de moler (Figura 2a), identificados en las muestras de sedimento extraídas de espacios de procesamiento dentro del sitio, sugieren el uso de este recurso en la elaboración de harinas y del almidón de batata (Ipomoea batatas), recuperado en el fragmento de mano de moler. Silicofitolitos de zapallo (Cucúrbita sp.) y microcarbones, reconocidos en la mano de moler, pueden indicar el molido de sus semillas (machacadas o tostadas). Tal práctica es acorde con el uso tradicional de ese recurso, junto con su pulpa y cáscara con fines tecnológicos y alimenticios.

A partir de la identificación de fitolitos de tala (Celtis tala) en una mano de moler, y de frutos quemados y silicofitolitos de la palmera pindó (Syagrus romanzoffiana) en sedimentos, se podría proponer un uso alimenticio, además del uso medicinal, tecnológico o de abrigo que tienen ambos recursos. Especialmente en algunas etnias se registra la fabricación de harinas con las fibras y la médula del tronco de las palmeras, mediante el machacado y el tamizado (Métraux y Baldus 1946).

De la tuna (Opuntia sp.) son utilizados sus frutos y cladodios como alimento o por sus propiedades medicinales. Además hay un uso tradicional de la tuna en la elaboración de pigmentos, como ligante o porque acoge a un parásito que brinda un tinte rojo: la cochinilla (Dactylopius coccus).

Plantas de tipo graminiformes, como las ciperáceas, identificadas en forma de silicofitolitos, pueden utilizarse con distintos usos tecnológicos, como la cestería, esteras o canoas, entre otros. También como alimento y medicinas. Particularmente en el área se reconoce una especie de importancia económica como el junco Schoenoplectus californicus (Scirpus californicus), que actualmente se explota para hacer esteras y canastos.

La situación cambia hacia los 3000 años AP, con el gradual descenso del nivel del mar, intercalado por pulsos transgresivos marinos que afectan la región (Bracco et al. 2005). La fisonomía del estuario entonces existente se transforma en un sistema de lagunas con amplias planicies de inundación (Beovide 2007, 2009, 2011a, 2011b). Los asentamientos se ubican en albardones arenosos, en las márgenes de dichas lagunas, protegidos de los vientos fríos del sur-oeste (Beovide 2007, 2009, 2011a).

Dos de los sitios identificados para ese momento de ocupación, Colonización y Gambe, presentan en sus espacios concheros en montículos y basureros conformados entre los 3000 y 2000 años AP, que han sido estudiados en profundidad (Beovide 2011a). Sin embargo no son los únicos, ya que se reconocen una serie de siete concheros en las márgenes de las paleolagunas, para ese período de tiempo (Beovide 2011a). Los sitios Puerto La Tuna hacia $c a .2000$ años AP y Ordeig (ca. 1600 años AP), no presentan concheros, pero si comparten con los sitios de Gambé y Colonización el registro arqueobotánico (Beovide 2011a, 2011b; Campos 2013).

Se ha propuesto que las sociedades ubicadas entre $c a$. 3000 y 1500 años AP, vinculadas con la presencia de concheros en algunos sitios, manejaron un territorio circunscrito fundamentalmente a la cuenca inferior del paleo-río Santa Lucía (Beovide 
Cuadro 5: Zea mays y otros restos vegetales identificados entre $c a .3000$ y 1500 años AP

\begin{tabular}{|c|c|c|c|c|c|c|c|}
\hline Taxón & $\begin{array}{l}\text { Nombre } \\
\text { común }\end{array}$ & $\begin{array}{c}\text { Micro-restos } \\
\text { botánicos }\end{array}$ & $\begin{array}{c}\text { Edad }{ }^{14} C \\
\operatorname{años} A P\end{array}$ & Sitio & $\begin{array}{l}\text { Exca- } \\
\text { vación }\end{array}$ & Muestra & Referencias \\
\hline Canna sp. & achira & silicofitolitos & ca. 2000 & La Tuna & III & $\begin{array}{l}\text { mano de } \\
\text { moler }\end{array}$ & $\begin{array}{l}\text { Beovide 2011a y b; } \\
\text { Campos } 2013\end{array}$ \\
\hline Zea mays & maíz & almidón & ca. 2000 & La Tuna & III & $\begin{array}{l}\text { mano de } \\
\text { moler }\end{array}$ & $\begin{array}{l}\text { Beovide 2011a y b; } \\
\text { Campos } 2013\end{array}$ \\
\hline Opuntia sp. & tuna & silicofitolitos & ca. 2000 & La Tuna & III & $\begin{array}{l}\text { mano de } \\
\text { moler }\end{array}$ & $\begin{array}{l}\text { Beovide 2011a y b; } \\
\text { Campos } 2013\end{array}$ \\
\hline Ciperáceas & & silicofitolitos & $2700-2300$ & Gambé & III & $\begin{array}{l}\text { mano de } \\
\text { moler }\end{array}$ & $\begin{array}{l}\text { Beovide 2007; Beovide } \\
\text { et al. } 2007,2011 \mathrm{a} \mathrm{y} \mathrm{b}\end{array}$ \\
\hline Ciperáceas & & silicofitolitos & $2700-2301$ & Gambé & III & $\begin{array}{l}\text { mano de } \\
\text { moler }\end{array}$ & $\begin{array}{l}\text { Beovide 2007; Beovide } \\
\text { et al. } 2007,2011 \mathrm{a} \mathrm{y} \mathrm{b}\end{array}$ \\
\hline Ciperáceas & & silicofitolitos & $2700-2300$ & Gambé & III & $\begin{array}{l}\text { mano de } \\
\text { moler }\end{array}$ & $\begin{array}{l}\text { Beovide 2007; Beovide } \\
\text { et al. 2007, 2011 a y b }\end{array}$ \\
\hline Zea mays & maíz & almidón & $2700-2300$ & Gambé & III & $\begin{array}{l}\text { mano de } \\
\text { moler }\end{array}$ & $\begin{array}{l}\text { Beovide 2007; Beovide } \\
\text { et al. } 2007,2011 \mathrm{a} \mathrm{y} \mathrm{b}\end{array}$ \\
\hline Ciperáceas & & silicofitolitos & $2700-2300$ & Gambé & III & $\begin{array}{l}\text { mano de } \\
\text { moler }\end{array}$ & $\begin{array}{l}\text { Beovide 2007; Beovide } \\
\text { et al. } 2007,2011 \mathrm{a} \mathrm{y} \mathrm{b}\end{array}$ \\
\hline Zea mays & maíz & almidón & $2700-2300$ & Gambé & III & $\begin{array}{l}\text { mano de } \\
\text { moler }\end{array}$ & $\begin{array}{l}\text { Beovide 2007; Beovide } \\
\text { et al. } 2007,2011 \mathrm{a} \mathrm{y} \mathrm{b}\end{array}$ \\
\hline Ciperáceas & & silicofitolitos & $2700-2300$ & Gambé & III & $\begin{array}{l}\text { mano de } \\
\text { moler }\end{array}$ & $\begin{array}{l}\text { Beovide 2007; Beovide } \\
\text { et al. 2007, 2011a y b }\end{array}$ \\
\hline Zea mays & maíz & almidón & $2700-2300$ & Gambé & III & $\begin{array}{l}\text { mano de } \\
\text { moler }\end{array}$ & $\begin{array}{l}\text { Beovide 2007; Beovide } \\
\text { et al. 2007, 2011a y b }\end{array}$ \\
\hline Ciperáceas & & silicofitolitos & $2700-2300$ & Gambé & III & $\begin{array}{l}\text { mano de } \\
\text { moler }\end{array}$ & $\begin{array}{l}\text { Beovide 2007; Beovide } \\
\text { et al. } 2007,2011 \mathrm{a} \mathrm{y} \mathrm{b}\end{array}$ \\
\hline $\begin{array}{l}\text { Cucurbita } \\
\text { maxima }\end{array}$ & zapallo & almidón & $2700-2300$ & Gambé & III & $\begin{array}{l}\text { mano de } \\
\text { moler }\end{array}$ & $\begin{array}{l}\text { Beovide 2007; Beovide } \\
\text { et al. 2007, 2011 a y b }\end{array}$ \\
\hline Zea mays & maíz & almidón & $2700-2300$ & Gambé & III & $\begin{array}{l}\text { mano de } \\
\text { moler }\end{array}$ & $\begin{array}{l}\text { Beovide 2007; Beovide } \\
\text { et al. } 2007,2011 \mathrm{a} \mathrm{y} \mathrm{b}\end{array}$ \\
\hline Zea mays & maíz & almidón & $2700-2300$ & Colonización & III & $\begin{array}{l}\text { mortero } \\
\text { doble }\end{array}$ & $\begin{array}{l}\text { Beovide 2007; } \\
\text { Beovide et al. 2011a y b; } \\
\text { Beovide y Campos } 2011\end{array}$ \\
\hline $\begin{array}{l}\text { Cucurbita } \\
\text { maxima }\end{array}$ & zapallo & almidón & $2700-2300$ & Colonización & III & $\begin{array}{l}\text { mortero } \\
\text { doble }\end{array}$ & $\begin{array}{l}\text { Beovide 2007; } \\
\text { Beovide et al. 2011a y b; } \\
\text { Beovide y Campos } 2011\end{array}$ \\
\hline Ciperáceas & & silicofitolitos & $2700-2300$ & Colonización & III & $\begin{array}{l}\text { mortero } \\
\text { doble }\end{array}$ & $\begin{array}{l}\text { Beovide 2007; } \\
\text { Beovide et al. 2011a y b; } \\
\text { Beovide y Campos } 2011\end{array}$ \\
\hline & $\begin{array}{l}\text { tubérculo } \\
\text { domestico }\end{array}$ & silicofitolitos & 1600 años $\mathrm{dC}$ & Ordeig & I & sedimento & Beovide y Campos 2009 \\
\hline Cannanáceas & & silicofitolitos & $2700-2300$ & Gambé & III & sedimentos & $\begin{array}{l}\text { Beovide 2007; Beovide } \\
\text { et al. 2007, 2011a y b }\end{array}$ \\
\hline Celtis tala & tala & silicofitolitos & $2700-2300$ & Gambé & III & sedimentos & $\begin{array}{l}\text { Beovide 2007; Beovide } \\
\text { et al. } 2007,2011 \mathrm{a} \mathrm{y} \mathrm{b}\end{array}$ \\
\hline Zea mays & maíz & almidón & $2700-2300$ & Gambé & III & sedimentos & $\begin{array}{l}\text { Beovide 2007; Beovide } \\
\text { et al. 2007, 2011a y b }\end{array}$ \\
\hline $\begin{array}{l}\text { Cucurbita } \\
\text { maxima }\end{array}$ & zapallo & silicofitolitos & 1600 años $\mathrm{dC}$ & Ordeig & I & sedimentos & $\begin{array}{l}\text { Beovide 2007; Beovide } \\
\text { et al. } 2007,2011 \mathrm{a} \mathrm{y} \mathrm{b}\end{array}$ \\
\hline Zea mays & maíz & almidón & 1600 años $\mathrm{dC}$ & Ordeig & I & sedimentos & $\begin{array}{l}\text { Beovide } 2007 \text {; Beovide } \\
\text { et al. } 2007,2011 \mathrm{a} \mathrm{y} \mathrm{b}\end{array}$ \\
\hline
\end{tabular}

2011a). Desarrollaron una serie de características más complejas de organización social que requieren articulación comunal y estrategias compartidas en torno a la formación de los concheros (Beovide 2011a). En general los concheros pueden ser considerados como marcadores del espacio y la memoria social que transforman de alguna manera el paisaje natural (De Blasis et al. 2007). Las especie de moluscos 
más abundante en los concheros es Erodona mactroides seguida de Ostrea equestris, Tagelus plebeius, Anomalocardia brasiliana y Mactra sp. (Beovide 2011a). Erodona mactroides es una especie $(\mathrm{ca} .3 \mathrm{~cm})$ que vive en sustratos arenosos. Su recolección pudo ser propiciada por las amplias planicies de inundación, asociadas a las lagunas formadas en dicho período (Beovide 2011a).

Además de los moluscos se identificó venado de campo (Ozotoceros bezoarticus), apereá (Cavia aperea) y tucu-tucu (Ctenomys sp.) entre otros (Beovide 2011a). Tiburón (Carcharhinus sp.), así como corvina negra (Pogonias cromis) y chucho (Myliobatis sp) son otros recursos marinos recuperados (Beovide 2011a).

Los espacios geográficos vinculados al abastecimiento de los recursos líticos se fueron acotando a la cuenca inferior del río Santa Lucía (Beovide 2009, 2011a). Se observa una mayor frecuencia de artefactos asociados con la molienda (Beovide et al. 2007), vinculados en primera instancia a la intensificación de las actividades de procesamiento de plantas (Beovide 2009). También se identifican objetos de adorno en concha (Erodona mactroides) y materias primas consideradas de «prestigio» como las «materias primas verdes» (malaquita, por ejemplo, cuya extracción está asociada a yacimientos de cobre) (Beovide 2009, 2011a).

Al conjunto de plantas presentes entre $c a$. 5000 y 4000 años AP se incorpora el maíz (Zea mays) (Beovide 2009). Este se ubica en los concheros de Gambé y Colonización, cuya presencia más temprana es acotada por fechados radiocarbonicos hacia ca. 3000 años AP (Beovide 2011a, 2013). El maíz (Zea mays) se identifica en forma de almidones, en artefactos de molienda (manos y morteros), así como en algunos sedimentos asociados a dichas actividades, en los sitios estudiados de ese período (Beovide et al. 2007).

Además de este cultígeno, se agrega la identificación de almidones de una especie de leguminosa, lupín (Lupinus albescens) (Campos 2013) en el conchero de Punta Espinillo (de fines del Holoceno medio). Este fue valorado por Jorge Baeza (2011), mediante estudios actualísticos, como un recurso de potencial importancia para la alimentación prehispánica.

El humedal mixohalino -que bordea el actual curso inferior de la cuenca del río Santa Lucía- se considera conformado entre $c a .2500$ y 2000 años AP, posterior al último pulso ingresivo marino que llega a cotas de ca. 2,5 msnm (Beovide 2007, Beovide et al.2010a). Ese momento de ocupación de la cuenca se caracteriza por la continuidad de aspectos ya observados en lapsos anteriores, entre ellos la disminución de la movilidad residencial y un uso más intenso de los recursos en radios inferiores a $10 \mathrm{~km}$ de los sitios (Beovide 2011a, Beovide et al. 2009). También se observa la consolidación de otros aspectos: la señalización de ciertos espacios como centros de actividad ritual; el desarrollo de un liderazgo posiblemente tribal hacia el Holoceno tardío y la existencia de redes de interacción regionales, las cuales son parte vinculante (en el plano del parentesco e intercambio) (Beovide 2009, 2011a).

Se han recuperado restos de corvina negra (Poogonias cromis), ciervo de los pantanos (Blastocerus dichotomus), coipo o nutria (Myocastor coypus), venado de campo (Ozotoceros bezoarticus), carpincho (Hydrocoerus hydrochaeris), tucu-tucu (Ctenomys sp.), armado (Doradidae), pecarí (Tayasuciedae), roedor (Rodentia), tortuga (Testudines) y aves (Beovide 2011a). 
Cuadro 6: Algunas de las plantas identificadas entre $c a$. 1500 y 400 años AP

\begin{tabular}{|c|c|c|c|c|c|c|c|}
\hline Taxón & $\begin{array}{l}\text { Nombre } \\
\text { común }\end{array}$ & $\begin{array}{l}\text { Micro-restos } \\
\text { botánicos }\end{array}$ & $\begin{array}{c}\text { Edad }{ }^{14} \mathrm{C} \\
\operatorname{años} A P\end{array}$ & Sitio & $\begin{array}{l}\text { Exca- } \\
\text { vación }\end{array}$ & Muestra & Referencias \\
\hline Ciperáceas & & silicofitolitos & ca. 700 & Mainumby & I & $\begin{array}{l}\text { cerámica } \\
\text { cara interna } \\
\text { y externa }\end{array}$ & Beovide 2011b; Campos 2013 \\
\hline Celtis tala & & silicofitolitos & ca. 700 & Mainumby & I & $\begin{array}{l}\text { cerámica } \\
\text { cara interna } \\
\text { y externa }\end{array}$ & Campos 2013; Malán et al. 2013 \\
\hline Opuntia sp. & tuna & silicofitolitos & ca. 700 & Mainumby & I & $\begin{array}{l}\text { cerámica } \\
\text { cara interna }\end{array}$ & Campos 2013; Malán et al. 2013 \\
\hline Zea mays & maíz & almidón & ca. 700 & La Tuna & III & $\begin{array}{l}\text { mano de } \\
\text { moler }\end{array}$ & Beovide 2011b; Campos 2013 \\
\hline Opuntia sp. & tuna & silicofitolitos & ca. 700 & La Tuna & III & $\begin{array}{l}\text { mano de } \\
\text { moler }\end{array}$ & Beovide 2011b; Campos 2013 \\
\hline $\begin{array}{l}\text { Cucurbita } \\
\text { maxima }\end{array}$ & zapallo & silicofitolitos & ca. 700 & La Tuna & III & $\begin{array}{l}\text { mano de } \\
\text { moler }\end{array}$ & Beovide 2011b; Campos 2013 \\
\hline Zea mays & maíz & almidón & ca. 700 & La Tuna & III & $\begin{array}{l}\text { mano de } \\
\text { moler }\end{array}$ & 2013 \\
\hline Zea mays & maíz & almidón & ca. 700 & La Tuna & III & $\begin{array}{l}\text { mano de } \\
\text { moler }\end{array}$ & Beovide 2011b; Campos 2013 \\
\hline $\begin{array}{l}\text { Cucurbita } \\
\text { maxima }\end{array}$ & zapallo & silicofitolitos & ca. 700 & Mainumby & I & $\begin{array}{l}\text { mano de } \\
\text { moler }\end{array}$ & Beovide 2011b; Campos 2013 \\
\hline $\begin{array}{l}\text { Cucurbita } \\
\text { maxima }\end{array}$ & zapallo & silicofitolitos & ca. 700 & Mainumby & I & mortero & Beovide 2011b; Campos 2013 \\
\hline Zea mays & maíz & almidón & ca. 700 & Mainumby & I & mortero & Beovide 2011b; Campos 2013 \\
\hline Ciperáceas & & silicofitolitos & ca. 700 & & I & mort & Beovide 2011b; C \\
\hline Celtis tala & & silicofitolitos & ca. 700 & Mainu & I & mortero & Beovide 2011b; Campos 2013 \\
\hline Opuntia $\mathrm{sp.}$ & tuna & silicofitolitos & ca. 700 & Mainumby & I & mortero & Beovide 2011b; Campos 2013 \\
\hline Canna sp. & achira & silicofitolitos & ca. 700 & La Tuna & III & sedimentos & Beovide 2011b; Campos 2013 \\
\hline Ciperáceas & & silicofitolitos & ca. 700 & La Tuna & III & sedimentos & Beovide 2011b; Campos 2013 \\
\hline Canna sp. & & silicofitolitos & ca. 700 & La Tuna & III & sedimentos & Beovide 2011b; Campos 2013 \\
\hline Zea mays & maíz & silicofitolitos & $\begin{array}{l}1540 \pm 65 \\
\text { años dC }\end{array}$ & La Tuna & VII & sedimentos & Campos 2013 \\
\hline Phaseolus sp. & porotos & silicofitolitos & $\begin{array}{l}1540 \pm 65 \\
\text { años dC }\end{array}$ & La Tuna & VII & sedimentos & Campos 2013 \\
\hline Baccharis sp. & carqueja & polen & $\begin{array}{l}1540 \pm 65 \\
\text { años dC }\end{array}$ & La Tuna & VII & sedimentos & Campos 2013 \\
\hline $\begin{array}{l}\text { Cucurbita } \\
\text { maxima }\end{array}$ & zapallo & almidón & $\begin{array}{l}1540 \pm 65 \\
\text { años dC }\end{array}$ & La Tuna & VII & $\begin{array}{l}\text { sedimentos, } \\
\text { asociado a } \\
\text { cerámica }\end{array}$ & Malán et al. 2013 \\
\hline Canno & achira & alm & $\begin{array}{l}1540 \pm 65 \\
\text { años dC }\end{array}$ & La Tuna & VII & $\begin{array}{l}\text { sedimentos, } \\
\text { asociado a } \\
\text { cerámica }\end{array}$ & Malán et \\
\hline
\end{tabular}

La producción alfarera se caracteriza por presentar cerámica decorada, asociada a sitios con funebria (Beovide 2009; Malán et al. 2013; Vallvé y Malán 2011; Vallvé et al. 2010). Más de 200 tipos distintos de diseños en la decoración cerámica se reportan en el sitio Puerto La Tuna, correspondientes a ese momento de ocupación del área. Eso tiene posibles implicaciones en la definición de lugares centrales vinculados con las redes de interacción entre las sociedades en torno al Río de la Plata (Beovide 2009, 2011a). También se reconocen torteros cerámicos, posiblemente usados para hilar, asociados a ese momento de ocupación (Beovide 2011a, 2011b).

En estudios funcionales sobre los contenedores cerámicos, se analizaron las caras internas/externas de los mismos, con distintos tipos de decoración (Malán et al. 
2013). En la cara interna de la cerámica se recuperó: a) achira (Canna sp.), en una muestra de cerámica pintada, b) tuna (Opuntia sp.), que junto con la especie antes mencionada se identifica para la muestra de cerámica corrugada, c) Ciperáceas, en una muestra de cerámica con decoración incisa, d) y tala (Celtis tala), en una muestra de cerámica sin decoración (Malán et al. 2013). A ello se suma la presencia de almidones gelatinizados en algunas de las muestras. En consecuencia, se ha postulado que se trata de vasijas utilizadas para procesar alimentos y posiblemente usadas en el hervido de farináceas (Malán et al. 2013). En esa línea de trabajo se han realizado también estudios de residuos de ácidos grasos sobre los contendores cerámicos que indican el posible consumo de grandes herbívoros, pescado y maíz (Malán et al. 2013). En sedimentos asociados a las muestras cerámicas se recupera zapallo (Cucurbita maxima) y achira (Canna sp.) (Campos 2013; Malán et al. 2013).

En instrumentos y sedimentos asociados a la molienda (manos y morteros) de los sitios Puerto La Tuna y Mainumby, se estudian silicofitolitos y almidones de las mismas especies reportadas para momentos anteriores de ocupación como: maíz (Zea mays), zapallo (Curubita maxima) y poroto (Phaseolus sp.). Estos se pueden consumir en distintas formas, a través del hervido y molido. Además se identificó tala (Celtis tala), tuna (Opuntia sp.) y Ciperáceas (Cuadro 6) (Beovide 2011a y 2011b; Campos 2013; Malán et al. 2013) y también se recuperó carqueja (Baccharis sp.) (Campos 2013) de potencial uso medicinal.

De las primeras crónicas de los viajeros y colonizadores del siglo XVI y XVII, en contacto con las poblaciones de la cuenca del río Santa Lucía y costa del Río de la Plata adyacente, se destacan dos: la de Pero Lope de Souza 1530-1532 y la de Hernando Arias de Saavedra-Hernandarias-1608. Ambas relatan el ambiente específico del siglo XVI y principios de XVII del área mencionada y mencionan algunas de las plantas usadas por dichas poblaciones. Cabe destacar que el sitio Puerto La Tuna presenta una ocupación que se remonta al siglo XVI (345-475 cal a.P, 1540 d.C, Beovide 2013), lo que permite desarrollar diversos acercamientos a su estudio que contemplen distintas hipótesis generadas desde la etnohistoria y la arqueología (Beovide 2003).

Sobre el medio ambiente, ambas crónicas describen el río Santa Lucía como «un río grande, todo arbolado a lo largo de él» (Lope de Souza 1958:125 [1530-1532]), «además de lo dicho tiene mucha leña» (Arias de Saavedra [1608] en Salaverry 1926:109) y mencionan que aprovechan una especie de «cebolletas/cardos» (Lope de Souza 1958:125 [1530-1532]). La presencia de embarcaciones reflejan (más allá de las inexactitudes) el uso del bosque y humedal: «salieron seis almadías (...) y en cuanto les di fueron a unos juncales y sacaron dos almadía (...) hechas de madera de cedro muy bien trabajada: remaban con unas palas muy largas que en su extremo tenían penachos y borlas de plumas; en cada almadía remaban 40 hombres de pie» (Lope de Souza 1958: 126, 132 [1530-1532]). Hernandarias también describe una situación similar «alle alli algunas canoas de los naturales de aquella costa» (Arias de Saavedra [1608] en Salaverry 1926:109). Pero Lópe de Sousa menciona en relación a la vivienda que «la gente era mucha; que le parecía que eran unos 600 hombres; que lo que parecían tiendas o carpas eran 4 esteras que formaban una casa cuadrada, descubiertas por arriba; tenían redes iguales a las nuestras». (Lope de Souza 1958:132 [1530-1532]). Se desprende de lo anterior que la vivienda y las redes de pesca po- 
drían haber sido fabricadas con los recursos del humedal como juncos, totora y Ciperáceas, entre otros.

\section{Discusión}

En lo expuesto hasta el momento se ha dejado deliberadamente de lado la interpretación del registro vegetal asociado a grupos lingüísticos/etnias, cuya delimitación arqueológica en la región presenta una serie de debilidades (Farías 2005). Sin dejar de pensar en la construcción histórica que define a los distintos grupos humanos, se trató de evitar en este análisis el uso de paradigmas que generen compartimientos estancos entre culturas basados en listas de rasgos distintivos (Arnold 2009; Beovide 2013). Para ello se exploraron ejes alternativos de interpretación del registro vegetal arqueológico, en su trayectoria temporal en la región. Los aspectos de trasmisión, comunicación e interrelación se han considerado dentro de amplios sistemas de relaciones ambiente/ cultura. De ellos emergen distintos tipos de asociaciones a lo largo del tiempo (Arnold 2009; Babot et al. 2012; Beovide 2013).

Del análisis del registro arqueobotánico regional realizado y en particular de la exploración de la trayectoria de las interacciones sociedades-plantas desde el Pleistoceno final, se puede destacar el reporte de aquellas especies vegetales con una presencia constante en el registro arqueológico. Por ejemplo: tala (Celtis tala), identificado en sitios arqueológicos de las llanuras pampeanas de Uruguay y Argentina. Su importancia en la alimentación, tecnología y medicina ya se ha reconocido en contextos más tardíos (González y Frere 2009). Se observa a su vez, desde el Holoceno medio al tardío, la continuidad temporo-espacial de ciertas «asociaciones» de plantas como: zapallo (Cucurbita maxima), achira (Canna sp.), poroto (Phaseolus sp.) y batata (Ipomoea batatas). A estas asociaciones se incorporan, de forma variable en tiempo y espacio, maíz (Zea mays) y ñame (Discorea sp.). Por otra parte, los diferentes tipos de palmeras se presentan como recursos ubicuos en la región, como lo es la araucaria (Araucaria angustifolia) para el sur de Brasil. Lo anterior se acompaña con el reconocimiento de la presencia extendida de instrumentos líticos (morteros, manos, entre otros) y de contenedores cerámicos que, en algunos sectores del área, se remontan al quinto milenio. Se infieren algunas técnicas de procesamiento comunes a la región, como el machacado para la producción de harinas, así como el hervido y el tostado de distintas partes de las plantas identificadas. Una de las implicaciones de lo expuesto radica en que la producción de alimentos parece ser un fenómeno social extendido en distintos hábitats de la región, lo que puede estar apoyando la idea de una amplia interacción entre las sociedades del pasado. Dejando de lado otros usos, se puede pensar que fundamentalmente las asociaciones, continuidades e incorporaciones vegetales observadas y extendidas en la región, pudieron obedecer a las preferencias alimentarias derivadas de la preparación de determinadas «recetas». Estas se podrían incluir dentro de tradiciones culinarias, pensadas como expresiones dinámicas, cuyo abordaje contribuye al entendimiento del rol del recurso botánico utilizado para el grupo humano (Babot et al. 2012). Estas preferencias alimentarias se pueden leer también en la extensión temporo-espacial de los saberes comunes en relación con el manejo o cultivo de determinadas plantas en sistemas socio-económicos similares o diversos. 
Las Ciperáceas, juncos y totora son recursos asociados a las tierras bajas y con una marcada presencia a lo largo del tiempo, lo que denota un marcado y extendido conocimiento de dichos ambientes en la región.

Por último, se desprende de lo expuesto que aún hay mucho por avanzar en el estudio de las trayectorias e interrelaciones entre las plantas y las sociedades en la región. La conjunción de distintas líneas de evidencias - con base en estudios bioantropológicos, isotópicos, de residuos, de silicofitolitos y almidones, etnohistóricos, antracológicos, entre otros- permitirá en un futuro mejores definiciones de aspectos vinculados a la dieta, así como tecnológicos e identitarios de las sociedades a partir del Pleistoceno final.

\section{Conclusiones}

El conocimiento sobre la domesticación de plantas estuvo presente y extendido en la región rioplatense mucho más temprano de lo que se venía manejado por los investigadores hasta hace unas décadas, como parte de un conjunto vasto de interacciones de dichas sociedades con el mundo vegetal.

Se puede reconocer un conjunto de plantas, tanto manejadas como cultivadas, relativamente ubicuas en la región, a partir del Pleistoceno final al Holoceno tardío. La trayectoria de las plantas presenta similitudes y continuidades que, entre otras cosas, se pueden explicar a partir de los gustos, saberes y tradiciones alimenticias.

Las interacciones entre las sociedades, en un sentido lato, han sido un vector de trasmisión de dicho conocimiento, contemplando las variaciones que se dan a nivel local en el uso de las plantas, asociadas a la particularidad histórica y dinámica del sistema natural.

Agradecimientos: Al apoyo recibido del Fondo Clemente Estable (ANIIFCE-2007-186/2011-5818) y de los integrantes del PIASL, DICYT-MEC. A la Lic. Elena Vallvé, Luis Vignolo y los evaluadores por los comentarios a este artículo.

\section{Referencias bibliográficas}

AmeGHINO, Florentino

1918 La antigüedad del hombre en el Plata. Buenos Aires: Editorial La Cultura Argentina.

ANDRADE, Tania y José LóPEZ

2000 «La emergencia de complejidad entre los cazadores recolectores de la Costa Atlántica meridional sudamericana». Revista de Arqueología Americana 17-19: 129175.

ARnold, Denise

2009 «Cartografías de la memoria. Hacia un paradigma más dinámico y viviente del espacio». Cuadernos de la Facultad de Humanidades y Ciencias Sociales 36: $205-$ 246. 
Babot, María, Salomón Hocsman, Romina Piccón y María Haros

2012 «Recetarios prehispánicos y tradiciones culinarias. Casos de La Puna Argentina», en Las manos en la masa: arqueologías, antropologías e historias de la alimentación en Suramérica, María del Pilar Babot, María Marschoff y Francisco Pazzarelli, eds., pp. 235-269. Córdoba: ISES-CONICET-UNT, Museo de Antropología, IDACOR-CONICET-UNC.

BABOT, María, Natalia MAzzIA y Cristina BAYóN

2007 «Procesamiento de recursos en la región pampeana bonaerense: aportes del instrumental de molienda de las localidades arqueológicas El Guanaco y Cerro La China», en Arqueología en las pampas II, Cristina Bayón, Nora Flegenheimer, María Isabel González de Bonaveri, Alejandra Pupio y Magdalena Frère, eds., pp. 635-657. Buenos Aires: Sociedad Argentina de Antropología.

BAEZA, Jorge

2011 «Lupinus albescens, una evaluación de su potencial productivo como posible uso por los grupos indígenas del Uruguay», en Resúmenes del III Congreso Latinoamericano de Arqueometría, Sebastián Gutiérrez,François-Philippe Hocquet, Manuel Rojas, Marcela Sepúlveda y Verónica Silva-Pinto, eds., p. 91. Arica: Universidad de Tarapaca.

BEBER, Marcus

2005 «O sistema do asentamento dos grupos ceramistas do planalto sul-brasilero: o caso da Tradicao Taquara/Itarare'». Documentos, Arqueologia no Rio Grande do Sul 10: 5-125.

Behling, Hermann, Valerio Pillar y Soraia BaUermanN

2005 «Late Quaternary Grassland (Campos), Gallery Forest, Fire, and Climate Dynamics, Studied by Pollen, Charcoal and Multivariate Analysis of the Sao Francisco de Assis Core in Western Rio Grande do Sul (Southeastern Brazil)». Review of Palaeobotany and Palynology 133: 235-248.

BEOVIDE, Laura

2003 «Crónicas del espacio costero, Uruguay», en Anais do XII Congreso da Sociedade de Arqueología Brasileira. Arqueologías da América Latina [CD-ROM], José de Morais, Marisa Coutinho Afonso, Dilamar Candida Martins, eds., pp. 1-13. San Pablo.

2007 «Un aporte al conocimiento del cambio climático holocénico desde la investigación arqueológica en el tramo medio del Río de la Plata (Uruguay)», en Semana de reflexión sobre cambio climático y variabilidad climática, pp. 110-121. Montevideo: Facultad de Agronomía, Universidad de la República.

2009 «Transformaciones productivas y dinámica costera: más allá del concepto de cazadores-recolectores prehispánicos», en XXII Simposio de Investigaciones Arqueológicas en Guatemala, Juan Laporte, Bárbara Arroyo y Héctor Mejía, eds., pp. 223-236. Guatemala: Asociación Tikal y Museo de Arqueología y Etnología de Guatemala.

2011a Arqueozoología de los depósitos conchilíferos de la cuenca inferior del río Santa Lucía, Uruguay. Tesis de doctorado inédita. Universidad de la República.

2011 b «La presencia de cultígenos desde el quinto milenio en el registro del curso medio Platense», en Avances y perspectivas en la Arqueología del Nordeste, Rosario Feuillet, María Belén Colasurdo, Julieta Sartori y Sandra Escudero, eds., pp. 155173. El Talar (Buenos Aires): Santísima Trinidad (ST Ser. Gráficos). 
2013 «Las sociedades prehistóricas de la cuenca del río Santa Lucía: una mirada desde la Epistemología de la Complejidad». Cuadernos del Instituto Nacional de Antropología y Pensamiento Latinoamericano - Series Especiales 1 (4): 81-95.

\section{Beovide, Laura y Sara CAmpos}

2009 «Inferencias paleoambientales derivadas de un contexto arqueológico de $c a .1600$ años AP a orillas del Plata», en Semana de reflexión sobre cambio y variabilidad climática, pp. 89-97. Montevideo: Facultad de Agronomía, Universidad de la República.

2011 «Aspectos paleoclimáticos provenientes del sitio arqueológico ‘Colonización' hacia los 2600 años $\mathrm{C}^{14} \mathrm{AP} »$, en Tercera semana de reflexión sobre la variabilidad y cambio climático en el Uruguay, pp. 73-82. Montevideo: Facultad de Agronomía, Universidad de la República.

Beovide, Laura, Maira Malán y Sara Campos

2010a «Evolución costera y sistemas de producción lítica en el Valle Inferior del Río Santa Lucía, Uruguay», en Arqueología de Cazadores Recolectores, Gabriel Cocco y Rosario Feuillet, comps., pp.135-155. El Talar (Buenos Aires): Santísima Trinidad (ST Ser. Gráficos).

Beovide, Laura, Virginia Mata y Sara CAMpos

2007 «Los artefactos de molienda en la ocupación humana de la cuenca inferior del Río Santa Lucía durante dos eventos transgresivos holocénicos», en Actas y Resúmenes del XVI Congreso Nacional de Arqueología Argentina, tomo 1, pp. 151-156. Jujuy: Universidad Nacional de Jujuy.

Beovide, Laura, Maira Malán, Sara Campos y Carolina Delgado

2009 «Manejo de los recursos naturales en un espacio funerario prehistórico: Puerto La Tuna», en La arqueología como profesión: los primeros 30 años. XI Congreso Nacional de Arqueología Uruguay, 2005, Laura Beovide, Carina Erchini y Gonzalo Figueiro, eds., pp.111-125. Montevideo: Asociación Uruguaya de Arqueología.

Beovide, Laura, Maira Malán, Sara Campos, Elena Vallvé y Marcela Caporale

2010b Arqueología en los humedales del Río Santa Lucía: 5000 años de prehistoria y evolución costera. Informe de proyecto ANII-FCE-2007-186. Montevideo, ms.

BERón, Mónica

2013 «La arqueología del sector occidental de la región pampeana. Trayectoria y reposicionamiento respecto a la arqueología nacional». Revista del Museo de La Plata, Sección Antropología 13 (87): 7-29.

Bitencourt, Ana y Patricia Krauspenhar

2006 «Possible Prehistoric Anthropogenic Effect on Araucaria angustifolia (bert.) O. Kuntze Expansion During the Late Holocene». Revista Brasileira de Paleontologia 9 (1): 15-26.

Bonomo, Mariano, Francisco Aceituno, Gustavo Politis y María Pochettino

2011a «Pre-Hispanic Horticulture in the Paraná Delta (Argentina): Archaeological and Historical Evidence». World Archaeology 43 (4): 554-575.

Bonomo, Mariano, María Colobig, Esteban Passegi, Alejandro Zucol y Mariana BreA 2011b «Multidisciplinary Studies at Cerro Tapera Vázquez site, Pre-Delta National Park, Argentina: The Archaeological, Sedimentological and Paleobotanical Evidence». Quaternary International 245 (1): 48-61 
Bonomo, Mariano, Gustavo Politis y Camila Gianotti

2011c «Montículos, jerarquía social y horticultura en las sociedades indígenas del delta del río Paraná (Argentina)». Latin American Antiquity 22 (3): 297-333.

BóRmidA, Marcelo

1964 «Las industrias líticas precerámicas del arroyo Catalán chico y del río Cuareim (Departamento de Artigas, R.O del Uruguay)». Revista di Scienze Prehistoriche 19 (1-4): 195-232.

Boyadjian, Celia

2007 Microfósseis contidos no cálculo dentário como evidência do uso de recursos vegetais nos sambaquis de Jabuticabeira II (SC) e Moraes (SP). Tesis de maestría inédita. Universidad de São Paulo.

BRACCO, Roberto

2006 «Montículos de la cuenca de la Laguna Merin: tiempo, espacio y sociedad». Latin American Antiquity 17: 511-540.

Bracco, Roberto, Laura Del Puerto, Hugo Inda y Carola CASTiÑEIRA

2005 «Mid-late Holocene Cultural and Environmental Dynamics in Eastern Uruguay». Quaternary International 132: 37-45.

Bracco, Roberto, María Fregeiro, Héctor Panarello, Rosario Odino y Beatriz Souto

2000 «Dieta, modos de producción de alimentos y complejidad», en Arqueología de las Tierras Bajas, Alicia Durán y Roberto Bracco, eds., pp. 227-248. Montevideo: Comisión Nacional de Arqueología, MEC.

Brea, Mariana, María Franco, Mariano Bonomo y Gustavo Politis

2013 «Análisis antracológico preliminar del sitio arqueológico Los Tres Cerros 1 (Delta superior del río Paraná), Provincia de Entre Ríos». Revista del Museo de la Plata, Sección Antropología 13 (87): 345-360.

CAmpos, Sara

2013 Análisis arqueobotánico proyecto ANII-FCE-2007-186 y 2012-5818. Informe al Museo Nacional de Antropología. Montevideo, ms.

Campos, Sara, Laura Del Puerto y Hugo Inda

2001 «Opal Phytolith Analysis: Its Applications to the Archaeological Record in Eastern Uruguay», en Phytoliths: Applications in Earth Sciences and Human History, Jean-Dominique Meunier y Fabrice Colin, eds., pp. 129-142. Lisse, Netherlands: A.A. Balkema Publishers.

Campos, Sara, Juana Olivera y Roberto Bracco

1993 Silicofitolitos: un aporte de la Paleoetnobotánica como técnica alternativa. Informe al Museo Nacional de Antropología. Montevideo, ms.

CAPDEMONT, Irina

2013 Arqueología de sociedades indígenas del litoral del Río Uruguay. Paisajes y Ocupaciones humanas. Saarbrücken: Publicia.

CAPdemont, Irina, Laura Del Puerto y Hugo IndA

2005 «Instrumentos de molienda: evidencias del procesamiento de recursos vegetales en la Laguna de Castillos (Rocha, Uruguay)». Intersecciones en Antropología 6: 153-166. 
Capdemont, Irina y Sebastián Pintos

2007 «Manejo prehistórico de recursos animales y vegetales en la cuenca de la laguna de Castillos, Rocha-Uruguay», en Arqueología argentina en los inicios de un nuevo siglo, Actas del XIV Congreso Nacional de Arqueología Argentina, Fernando Oliva, Nélida de Grandis y Jorge Rodríguez, eds., tomo 1, pp. 143-157. Rosario: Universidad Nacional de Rosario.

Castillos, Andrea

2004 «Excavaciones y museo: profundizando en el conocimiento de los grupos 'ceramistas' del litoral (Río Negro, Uruguay)», en Actas del X Congreso Nacional de Arqueología Uruguaya. La arqueología uruguaya ante los desafios del nuevo siglo, Laura Beovide, Isabel Barreto y Carmen Curbelo, eds. Montevideo, Asociación Uruguaya de Arqueología. Publicación en CD.

Cavallotto, José, Roberto Violante y Gerardo Parker

2004 «Sea-Level Fluctuations during the Last 8600 Years in the de La Plata River (Argentina)». Quaternary International 114: 155-165.

Coronel, Nelson, Jorge Spoturno y Carlos Theune

1980 Estudio geomorfológico de los áridos para la construcción en Montevideo, producción, reserva y nuevos yacimientos. Informe. MIE, Programa de colaboración alemana. Montevideo, ms.

De Blasis, Paulo, Andreas Kneip, Rita Scheel-Ybert, Paulo Giannini y María Gaspar

2007 «Sambaquis e paisagem: dinâmica natural e Arqueologia regional no litoral do sul do Brasil». Arqueología Suramericana 3 (1): 29-61.

De MASI, Marco

2005 «Arqueologia das terras altas do sul do Brasil. O baixo vale do Rio Canoas, SC», en Anais Eletrônicos do XIII Congresso da Sociedade de Arqueologia Brasileira: arqueologia, patrimônio e turismo, pp 20. Campo Grande: SAB.

Del Puerto, Laura y Sara CAmpos

1999 «Silicofitolitos: un abordaje alternativo de la problemática arqueobotánica del este del Uruguay», en En los tres reinos: prácticas de recolección en el Cono Sur de América, Carlos Aschero, María Korstanje y Patricia Vuoto, eds., pp.141-150. San Miguel de Tucumán: Ediciones Magna Publicaciones.

Del Puerto, Laura y Hugo IndA

2005 «Paleoetnobotánica de los constructores de Cerritos del noreste de Uruguay: análisis de silicofitolitos de la estructura monticular yale27 y su entorno». TAPA, Traballos de Arqueoloxía e Patrimonio 36: 109-120.

Del Puerto, Laura, Hugo Inda y Alejandra WürschmidT

2000 «Fitolitos de cucurbitáceas americanas cultivadas arqueológicas y actuales», en $X I$ Simposio Argentino de Paleobotánica y Palinología, Libro de Resúmenes, p. 25. Tucumán: UNLP, SAPP.

Del Puerto, Laura, Roberto Bracco, Hugo Inda, Ofelia Gutiérrez, Daniel Panario y Felipe García

2013 «Assessing Links between Late Holocene Climate Change and Paleolimnological Development of Peña Lagoon Using Opal Phytoliths, Physical, and Geochemical proxies». Quaternary International 287: 89-100. 
DíAz, Antonio y Marita FornAro

1977 «Intento de sistematización de las modalidades alfareras del litoral Uruguayo», en VEncuentro de Arqueología del Litoral, pp. 165-174. Fary Bentos: Ministerio de Educación y Cultura.

FARÍAS, María

2005 El guaraní arqueológico meridional: entre el axioma y la heterodoxia. Tesis doctoral inédita. Pontificia Universidad Católica de Rio Grande Do Sul.

GianotTi, Camila

2000 «Monumentalidad, ceremonialismo y continuidad ritual». TAPA, Traballos de Arqueoloxía e Patrimonio 19: 87-102.

2005 «Intervenciones arqueológicas en el cerrito 27 del Conjunto Lemos». TAPA, Traballos de Arqueoloxía e Patrimonio 36: 79-98.

Gianotti, Camila, Laura Del Puerto, Hugo Inda e Irina Capdemont

2013 «Construir para producir. Pequeñas elevaciones en tierra para el cultivo de maíz en el sitio Cañada de los Caponcitos, Tacuarembó (Uruguay)». Cuadernos del Instituto Nacional de Antropología y Pensamiento Latinoamericano - Series Especiales 1: 12-25.

GonzÁLEz, María

2005 Arqueología de alfareros, cazadores y pescadores pampeanos. Buenos Aires: Sociedad Argentina de Antropología.

GonzÁLEz, María y Magdalena Frere

2009 «Talares y paisaje fluvial bonaerense: arqueología del río Salado». Intersecciones en Antropología 10: 249-265.

Illescas, Franco, Adriana CAÑIzo, María Musaubach y Mónica Berón

2012 «De ollas, aceites y otras yerbas. Análisis complementarios sobre alfarería pampeana», en Las manos en la masa. Arqueologías, antropologías e historias de la alimentación en Suramérica, María del Pilar Babot, María Marschoff y Francisco Pazzarelli, eds., pp. 389-407. Córdoba: ISES-CONICET-UNT, Museo de Antropología, IDACOR-CONICET-UNC.

IMBELLONI, José

1939 «Estado actual de la sistemática del hombre con referencia a América». Physis 16: 309-321.

IRIARTE, José

2006a «Landscape Transformation, Mounded Villages and Adopted Cultigens: The Rise of Early Formative Communities in South-Eastern Uruguay». World Archaeology 38: 644-663.

2006 b «Vegetation and Climate Change Since $14,810{ }^{14} \mathrm{C}$ B.P. in Southeastern Uruguay and Implications for the Rise of Early Formative Societies». Quaternary Research 65: 20-32.

2007a «New Perspectives on Plant Domestication and the Development of Agriculture in the New World», en Rethinking Agriculture: Archaeological and Ethnoarchaeological Perspectives, Tim Denham, José Iriarte y Luc Vyrdaghs, eds., pp. 167-189. Walnut Creek: Left Coast Press.

2007b «Emerging Food-Production Systems in the La Plata Basin: Los Ajos Site», en Rethinking Agriculture: Archaeological and Ethnoarchaeological Perspectives, Tim Denham, José Iriarte y Luc Vyrdaghs, eds., pp. 254-270. Walnut Creek: Left Coast Press. 
IRIARTE, José y Hermann BEHLING

2007 «The Expansion of Araucaria Forest in the Southern Brazilian Highlands during the Last 4000 Years and its Implications for the Development of the Taquara/Itararé Tradition». Environmental Archaeology 12: 115-127.

IRIARTE, José, Christopher Gillam y Oscar Marozzi

2008 «Monumental Burials and Memorial Feasting: An Example from the Southern Brazilian Highlands». Antiquity 82: 947-961.

Iriarte, José, Irene Holst, José LóPEz y Leonel CABrera

2001 «Subtropical Wetland Adaptations in Uruguay during the Mid-Holocene: An Archaeobotanical Perspective», en Enduring Records: The Environmental and Cultural Heritage of Wetlands, Barbara Purdy, ed., pp. 61-70. Oxford: Oxbow Books.

Iriarte, José, Irene Holst, Oscar Marozzi, Claudia Listopad, Eduardo Alonso, Andrés RINDERKNECHT Y Juan MONTAÑA

2004 «Evidence for Cultivar Adoption and Emerging of Complexity during the MidHolocene in the La Plata Basin». Nature 34: 614-617.

IRIARTe, José, Oscar Marozzi y Christopher Gillam

2010 «Monumentos funerarios y festejos rituales: complejos de recintos y túmulos Taquara/ Itararé en el Dorado, Misiones (Argentina)». Arqueología Iberoamericana 6: 25-38.

Kern, Arno, José Souza y Fernando SefFner

1989 «Arqueologia de salvamento e a ocupacao pré-histórica do vale do Rio Pelotas (Municípios de Bom Jesus e Vacaria)». Veritas 35: 99-127.

Lope De Souza, Pero

1958 «Diario de navegación (1530-1532)», en Viajeros y visitantes del Uruguay. Apartado de la Revista de la Sociedad de Amigos de la Arqueología, Horacio Arredondo, ed., pp. 134-140. Montevideo: Editorial Siglo Ilustrado.

López, José

2001 «Las estructuras tumulares (cerritos) del Litoral Atlántico Uruguayo». Latin American Antiquity 12 (3): 231-255.

2013 «Early Human Occupation of Uruguay: Radiocarbon Database and Archaeological Implications». Quaternary International 301: 94-103.

LóPEZ, José y Roberto BRACCO

1992 «Relación hombre-medio ambiente en las poblaciones prehistóricas de la zona Este del Uruguay», en Archaeology and Environment in Latin America, Omar Ortiz-Troncoso $y$ Thomas Van der Hammen, eds., pp. 259-282. Amsterdam: Universitat van Amsterdam

2010 Minuanos: notas y apuntes para el estudio y la arqueología del territorio Guenoa/ Minúan. Montevideo: Linardi y Risso.

LOPONTE, Daniel

2008 Arqueología del Humedal del Paraná inferior (bajíos ribereños meridionales). Buenos Aires: Ediciones Riel.

Loponte, Daniel y Alejandro Acosta

2007 «Horticultores amazónicos en el Humedal del Paraná Inferior: los primeros datos Isotópicos de la dieta», en Arqueología en las Pampas, Cristina Bayón, Alejandra Pupio, María Isabel González, Nora Flegenheimer y Magdalena Frére, eds., 1: 7593. Buenos Aires: Sociedad Argentina de Antropología. 
Loponte, Daniel, Alejandro Acosta y Javier Musali

2004 «Complejidad social: cazadores-recolectores-horticultores en la región pampeana», en Aproximaciones contemporáneas a la arqueología Pampeana. Perspectivas teóricas, metodológicas, analíticas y casos de estudio, Gustavo Martínez, María Gutiérrez, Rafael Curtoni, Monica Berón y Patricia Madrid, eds., pp. 41-60. Olavarría: UNCPBA.

Malán, Maira, Elena Vallve, Ana Malvar y Sara CAmpos

2013 «Sobre vasijas y sus decoraciones: un acercamiento a sus funciones y usos». Cuadernos del Instituto Nacional de Antropología y Pensamiento Latinoamericano Series Especiales 1 (2): 61-71.

Martínez, Sergio, Alejandra Rojas, Martín Ubilla, Mariano Verde, Daniel Perea y Graciela PIÑEIRO

2006 «Molluscan Assemblages from the Marine Holocene of Uruguay: Composition, Geochronology, and Paleoenvironmental Signals». Ameghiniana 43 (2): 385-397.

Meroni, María, María Paleo, María Pochettino y Verónica Lema

2010 «Procesamiento y consumo de vegetales por grupos cazadores-recolectores del Holoceno tardío en Partidos de Magdalena y Punta Indio, Provincia de Buenos Aires», en Mamül Mapu: pasado y presente desde la arqueología pampeana, Mónica Berón, Leandro Luna, Mariano Bonomo, Claudia Montalvo, Claudia Aranda y Manuel Carrera Aizpitarte, eds., pp. 215-226. Ayacucho (Buenos Aires): Libros del Espinillo.

MÉTRAux, Alfred y Herbert Baldus

1946 «The Guayakí», en Handbook of South American Indians, Julian Steward, ed., vol. 1, pp. 435-444. Washington: Smithsonian Institution.

MiLLER, Eurico

1971 «Pesquisas arqueologicas efectuadas no Planalto Meridional, Rio Grande do Sul (rios Uruguai, Pelotas, e das Antas)». Publicações Avulsas 15: 37-60.

1987 «Pesquisas Arqueológicas Paleoindígenas no Brasil Occidental». Estudios Atacameños 8: 37-61.

Misión DE RESCATE ARQUEOLÓGICO

1989 Misión de rescate arqueológico, Salto Grande, 2 tomos. Montevideo: MEC.

Olivero, Juana y Sara CAmpos

1997 «Análisis de las partículas biosilíceas en la matriz del sitio arqueológico CH2DO1, San Miguel, Rocha, Uruguay», en Arqueología uruguaya hacia el fin del milenio. IX Congreso Nacional de Arqueología, tomo 1, pp. 539-543. Montevideo: AUA Gráficos del Sur.

Politis, Gustavo, Gustavo Martínez y Mariano Bonomo

2001 «Alfarería temprana en sitios de cazadores recolectores de la Región Pampeana (Argentina)». Latin American Antiquity 12 (2): 167-181.

Politis, Gustavo, Pablo Massineo y Cristian Kaufmann

2004 «El poblamiento temprano de las llanuras pampeanas de Argentina y Uruguay». Complutum 15: 207-224.

RiBEIRo, Pedro

1999-2000 «A Tradiçao Taquara e as casas subterraneas no Sul do Brasil». Revista de Arqueología Americana 17-18-19: 9-50. 
RodRíGuEZ, Jorge

1992 «Arqueología del sudeste de Sudamérica», en Prehistoria sudamericana: nuevas perspectivas, Betty Meggers, ed., pp. 177-209. Santiago de Chile: Editorial Universitaria.

2008 «Arqueología de humedales en la Provincia de Corrientes (Argentina)», en Entre la tierra y el agua. Arqueología de humedales en Sudamérica, Daniel Loponte y Alejandro Acosta, eds., pp. 165-191.Buenos Aires: Asociación Amigos del Instituto Nacional de Antropología y Pensamiento Latinoamericano.

2010 «Sistemas de asentamiento y subsistencia en dos entidades culturales del nordeste argentino», en Arqueología argentina en los inicios de un nuevo siglo. Actas del XIV Congreso Nacional de Arqueología Argentina, Fernando Oliva, Nélida de Grandis y Jorge Rodríguez, eds., tomo 3, pp. 473-485. Rosario: Universidad Nacional de Rosario.

SALAVERRY, Juan

1926 Los charrúas y Santa Fe. Montevideo: Gómez y Cía.

SÁnchez, Jorge, Milagros Colobig, Alejandro Zucol, Gustavo Politis, Mariano Bonomo y Carola CASTIÑEIRA

2013 «Análisis del uso prehispánico de los recursos vegetales a partir del registro biosilíceo del sitio arqueológico Los Tres Cerros 1 (Victoria, Entre Ríos). Primeros resultados». Darwiniana, nueva serie 1(2): 201-219.

SANS, Mónica

1988 Las poblaciones prehistóricas del Uruguay. Montevideo: Facultad de Humanidades y Ciencias de la Educación.

SCHEEL-YBERT, Rita

2001 «Man and Vegetation in Southeastern Brazil during the Late Holocene». Journal of Archaeological Science 28: 471-480.

Scheel-Ybert, Rita, Sabine Eggers, Cecilia Petronilho, Celia Boyadjian, Verónica Wesolowski, Paulo De Blasis y María Gaspar

2003 «Sistema de subsistência e modo de vida dos construtores de sambaquis: uma abordagem multidisciplinar». Revista de Arqueología, SAB 16: 109-137.

Schmitz, Pedro

1991 «Migrantes da Amazonia: a tradiçao Tupiguarani», en Arqueología Prehistórica do Rio Grande do Sul, Arno Kern, ed., pp. 295-330. San Leopoldo: UNISINOS.

2000-01 «Ambientes holocenicos e surgimento de sistemas culturais». Revista de Arqueologia 14-15: 87-96.

SERRANO, Antonio

1972 «Líneas fundamentales de la arqueología del Litoral (una tentativa de periodización)». Publicaciones del Instituto de Antropología 32.

SuÁREZ, Rafael

2011 Arqueología durante la transición Pleistoceno Holoceno en Uruguay. Componentes paleoindios, organización de la tecnología lítica y movilidad de los primeros americanos. BAR International Series 2220. Oxford: Archaeopress.

TENORIO, María

1999 «Coleta, processamento e início da domesticação de plantas no Brasil», en Préhistória de terra brasili, Maria Cristina Tenório, ed., pp. 259-272. Rio de Janeiro: EDUFRJ. 
VALLVÉ, Elena y Maira MALÁN

2011 «Caracterización de un conjunto de cerámica decorada del litoral platense a partir de análisis multivariantes», en Actas del II Congreso Latinoamericano de Arqueometría, Luisa Vetter, Rafael Vega-Centeno, Paula Olivera y Susan Petrick, eds., pp. 431-440. Lima: IPEN-UNI-OEI.

Vallvé, Elena, Maira Malán y Ana Malvar

2010 «Zigzagueando entre La Tuna y Arazatí: vinculaciones decorativas entre dos sitios cerámicos con actividades funerarias», en Arqueología argentina en el bicentenario de la Revolución de Mayo, Actas del XVII Congreso Nacional de Arqueología Argentina, tomo 1, pp. 175-180. Mendoza: Universidad Nacional de Cuyo.

WeSOLOWSKI, Verónica

2000 A prática da horticultura entre os construtores de sambaquis e acampamentos litorâneos da região da Baía de São Francisco, Santa Catarina: uma abordagem bio-antropológica. Tesis de maestría inédita. Universidad de São Paulo.

2007 Cáries, desgaste, cálculos dentários e micro-resíduos da dieta entre grupos préhistóricos do litoral norte de Santa Catarina: é possível comer amido e não ter cárie? Tesis doctoral inédita. Escola Nacional de Saúde Pública, Fundação Osvaldo Cruz.

Zucol, Alejandro, Mariana BreA y Diana Mazzanti

2008 «Análisis de restos orgánicos presentes en cerámicas arqueológicas de las sierras de Tandilia (provincia de Buenos Aires, Argentina)», en Matices interdisciplinarios en estudios fitolíticos y de otros microfósiles, Alejandra Korstanje y María del Pilar Babot, eds., pp. 201-208. BAR International Series 1870. Oxford: Archaeopress. 